\title{
Amirah El-Haddad* \\ Picking Winners: Identifying Leading Sectors for Egypt and Tunisia Using the Product Space Methodology
}

https://doi.org/10.1515/rmeef-2019-0015

Received June 28, 2019; accepted May 10, 2020

\begin{abstract}
The structural transformation of countries moves them towards more sophisticated, higher-value products. Network analysis, using the Product Space Methodology (PSM), guides countries towards leading export sectors. The identification process rests on two pillars: (1) available opportunities, that is, products in the product space that the country does not yet export which are more sophisticated than its current exports; and (2) the stock of a country's accumulated productive knowledge and the technical capabilities that, through spillovers, enable it to produce slightly more sophisticated products. The PSM points to a tradeoff between capabilities and complexity. It identifies very basic future products that match the two countries' equally basic capabilities. Top products are simple animal products, cream and yogurt, modestly sophisticated plastics, metals and minerals such as salt and sulphur for Egypt; and slightly more sophisticated products such as containers and bobbins (plastics) and broom handles and wooden products for Tunisia, which is the more advanced of the two countries. A more interventionist approach steers the economy towards maximum sophistication, thus identifying highly complex manufactured metals, machinery, equipment, electronics and chemicals. Despite pushing for economic growth and diversification, these sectors push urban job creation and require high-skill workers, with the implication that low-skilled labour may be pushed into unemployment or into low-value informal jobs. A middle ground is a forward-looking strategy that takes sectors' shares in world trade into account.
\end{abstract}

Keywords: picking winners, industrial policy, product space methodology, Egypt, Tunisia, manufacturing

\footnotetext{
${ }^{\star}$ Corresponding author: Prof. Dr. Amirah El-Haddad, PhD, Sustainable Economic and Social Development Department, Stabilization and Development in the Middle East and North Africa, German Development Institute, Tulpenfeld 6, D-53113, Bonn, Germany; Faculty of Economics and Political Sciences, Cairo University, Giza, Egypt; and Economic Research Forum, Research Fellow, Cairo, Egypt, E-mail: Amirah.El-Haddad@die-gdi.de
} 


\section{Introduction}

With their increased liberalization efforts Egypt and Tunisia's export performance has significantly improved, especially as of 2003, from just an average of $4 \%(6 \%)$ export growth rate in the nineties to double digit growth rates of $20 \%$ (16\%) during 2002-2007 for Egypt and Tunisia respectively. Unfortunately, these impressive growth rates could not be sustained as the two economies were hit by the financial crisis of 2008. Their export growth rates plummeted by over 10 percentage points during 2008-2010. The upheavals of the Arab Spring likely caused yet again another drop, where export growth rates have turned negative (Table 1). GDP per capita growth rates have closely followed these trends (Figure 1). As a result the two countries face growing economic challenges, most notably youth unemployment (Assaad and Krafft 2016; Djeflat 2013). Export diversification, growth and structural transformation create viable opportunities for private-sector growth and expansion, and thereby higher value added employment than is currently available (cf. van Eekelen, de Luca, and Ismail 2001). ${ }^{1}$ Thus, this paper's main goal is to identify Egypt and Tunisia's future export advantages by using variants of the Product Space Methodology (PSM). The PSM is a recent approach that guides countries as to what sectors to pick for support as engines of export growth, and in turn for overall growth and development (Hausmann and Hidalgo 2007).

Egypt and Tunisia provide particularly interesting cases since, despite their common political history and the similar paths they have taken in economic policy (El-Haddad 2020; Weipert-Fenner and Wolff 2020; El-Haddad 2018), they have achieved somewhat different results. Both have a concentration of exports in hydrocarbons and a limited degree of complexity of their export baskets as will be shown below. Despite these similarities, Tunisia achieved greater structural transformation as this paper shows. ${ }^{2}$ The two countries' varying performance

\footnotetext{
1 On the established positive relation between export diversification and growth in both developed and developing countries cf. Kalaitzi and Cleeve 2017; Kalaitzi and Chamberlain 2019; Hosseini and Tang 2014; Hamed, Hadi and Hossein 2014; Gözgör and Can 2017; Herzer et al. 2006; de Ferranti, Perry, Foster, Lederman and Valdés 2005; Feenstra, Lipsey, Deng, Ma and Mo 2005; Al Marhubi 2000. Some literature showed that it is so at least up to a lower bound of incomes of highincome countries, e.g. Brenton, Saborowski et al. 2009; Cadot, Carrere and Strauss Kahn 2008; Klinger and Lederman 2004; Sannassee, Seetanah and Lamport 2014.

2 Structural transformation is defined as long-term, persistent shifts in the sectoral composition of an economy. It is a process that involves moving away from primary sectors such as agriculture and mining towards manufacturing or high-value services, including the diversification of the productive structure of the economy, towards more sophisticated production (cf. Kuznets, 1971; Pasinetti, 1981; Ricardo, 1817; Rodrik, 2007).
} 
Table 1: Exports of goods and services period growth rates.

\begin{tabular}{lrrrr}
\hline & $\mathbf{1 9 9 1 - 2 0 0 2}$ & 2003-2007 & 2008-2010 & 2011-2016 \\
\hline Egypt & $4 \%$ & $20 \%$ & $7 \%$ & $-6 \%$ \\
Tunisia & $6 \%$ & $16 \%$ & $5 \%$ & $-6 \%$ \\
\hline
\end{tabular}

Source: author's calculations based on WDI (2018).

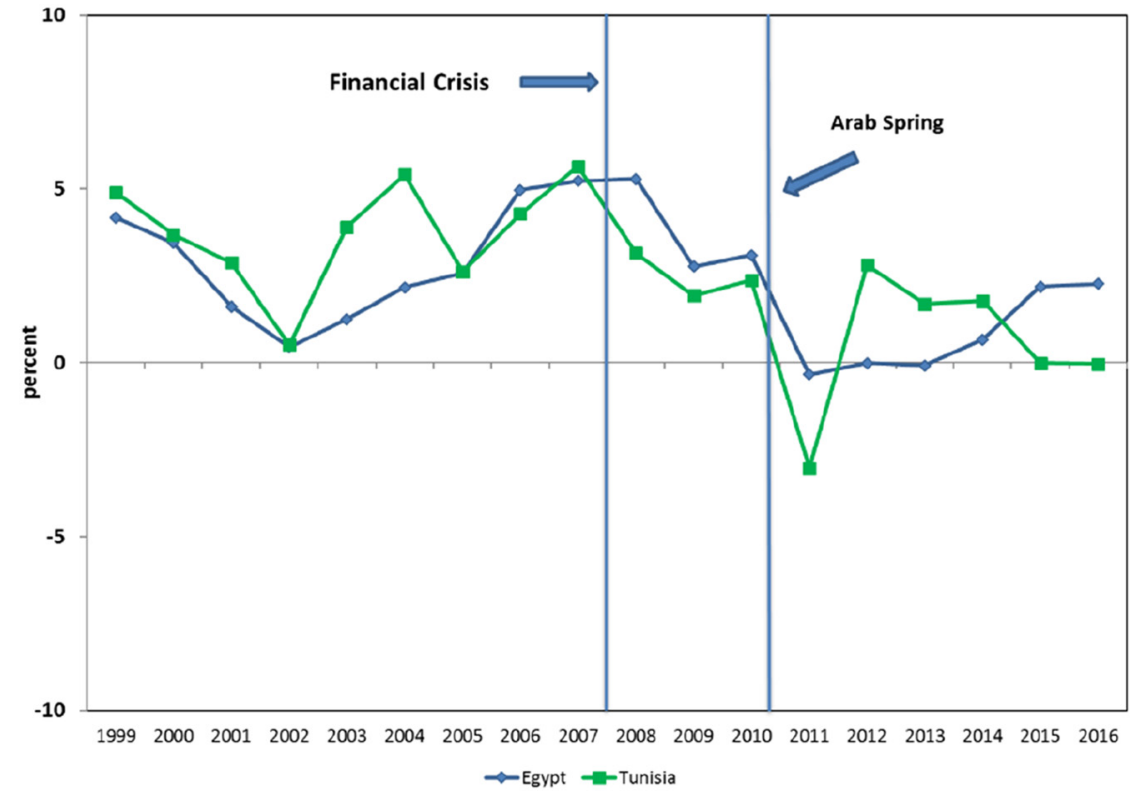

Figure 1: GDP per capita growth rate.

Source: Author's calculations based on WDI (2018).

allows us to explore these differences. To what extent have Tunisia's initial steps towards diversification and upgrading enabled the country to take more ambitious steps in the future?

Although there is consensus for the necessity of export diversification and structural change, there is no consensus about how to steer the economy towards that change. Recent models have tried to predict the most productive patterns of diversification, and thus trade, to enhance growth. The PSM approach uses a network analysis of the product space as the basis for an active industrial policy to steer the economy towards sectors that are similar in terms of the capabilities, skills and knowledge required for their production to 
those of currently exported products (Hausmann, Hwang and Rodrik 2005; Hausmann and Klinger 2006; Hausmann, Klinger and Lopez-Calix 2010; Hausmann et al. 2011; Hidalgo, Klinger, Barabási et al. 2007). These new sectors have slightly higher levels of sophistication and will therefore gradually lead the countries towards more sophistication in the future.

By concentrating on the proximity of the currently exported products to the ones that will be potentially produced in the future, this approach contrasts with the unbalanced growth theory, which has long argued that developing countries should diversify through the development of forward and backward linkages (see Hirschman 1969; Singer 1958; Streeten 1969). Such diversification for open economies has sometimes failed. Take, for example, two industries that are strongly linked in the garment value chain of production: raw cotton and textiles. Driven by Egypt's production of highquality, long-staple cotton, the country has always tried to develop its textiles industry. With Egypt's accession to the World Trade Organization, which exposed the country to international competition, this industry has nearly vanished (El-Haddad 2012), despite the obvious forward and backward linkages between the two. The PSM provides an explanation for this failure. It lies in the fact that the capabilities and skills required to produce raw cotton, such as climate and water, are very different from those required for the production of the capital-intensive textiles industry. Therefore, if a country produces cotton lint successfully, that does not automatically imply that it will successfully produce textiles. Indeed, high-quality Egyptian cotton lint has been turned into coarse yarns, which produce poorly woven fabrics. Once the import bans on textiles were lifted in 1998 and previously prohibitive import tariffs were substantially reduced from 2000 to 2004, the textiles industry collapsed as the country witnessed a surge of imported fabrics (ibid.). Thus, the PSM approach, which identifies the future natural export diversification structure of countries, diverges substantially from the standard approach that treats industries as being vertically connected through forward and backward linkages.

Two related papers are relevant. Attallah and Srour (2014) showed that Lebanon has managed to export a number of highly sophisticated products with hardly any government intervention. In contrast, this paper provides the list of potential export products that industrial policy in Egypt and Tunisia should target in order to achieve greater structural transformation. This paper complements Bustos and Yildrim (2017) in that it provides detailed lists of sectors for two specific countries as opposed to their more general aggregated results for all Arab countries. 
An introduction to the Product Space Methodology and of the two countries' positions in that space is presented in Section 2. Section 3 presents results of the PSM, as well as two of its variants. These results are followed by a discussion of potential shortcomings of the methodology. Section 5 concludes. To avoid a breakage in the technical flow of the paper the two countries' economic country contexts including some basic differences in market orientation, trade openness and export diversification is discussed in Annex A1.

\section{The Product Space Methodology}

The previous analysis identified a relatively large degree of hydrocarbon concentration of exports and a limited degree of complexity of the export baskets of both Tunisia and Egypt, with Egypt being worse of the two. The sophistication and diversification of exports are distinct goals to any active industrial policy, simply because there is an established positive relationship between export diversification and growth as highlighted earlier. Because exports boost economies of scale, they tend to become the activities with the highest productivity levels in the country. The Product Space methodology is a recent approach that guides countries as to what sectors to pick for support as engines of export growth, and in turn for overall growth and development. The next section describes the methodology, then moves on to the resulting policy prescriptions of this analysis for Egypt and Tunisia.

\subsection{Product Space Analysis}

This approach is the outcome of the combined efforts of the following scholars: Hausmann et al. 2005, Hausmann and Klinger 2006, Hidalgo et al. 2007, Hidalgo and Hausmann 2009, Hausmann et al. 2010 and Hausmann et al. 2011. Drawing on the tools of network analysis, they empirically map the product space for exported products. Since the set of capabilities requisite for one existing industry is easily redeployed to another new industry, spillover effects are at the heart of the analysis. It is more likely that a country producing asparagus will be able to produce artichokes as well, because there will be rural infrastructure in the appropriate climatic zones suitable for both products in addition to cold storage transportation systems, customs and regulatory regimes, and services that support the export of fresh produce, for example product approval and phytosanitary permits. Thus, it is easier to embark upon establishing an industry when a similar one already exists, as the set of 
requisite capabilities can be easily deployed to another new industry. The same is not true of an advanced crude oil production industry. Engineers, gravimeters, magnetometers, drilling rigs and pipelines used in oil extraction and transport are much less suited for artichokes and more difficult to redeploy for their cultivation and export (Hausmann et al. 2010). Artichoke and oil production are therefore far away from each other in the product space, whilst artichoke and asparagus are not. This way of looking at things implies path dependence, meaning that what a country produces today affects what it could produce tomorrow.

In Hausmann and Klinger 2006, Hausmann and Hidalgo 2007, Hausmann et al. 2005, 2009, 2010, 2011, the product space is constructed by connecting each exported product to its nearest neighbour in terms of proximity. Proximity here measures the closeness of capabilities and embedded knowledge of one product in relation to another in the product space. Formally, it is thus the probability that, if a product is exported, the other is exported as well; it is measured as the minimum of the pairwise conditional probability of having comparative advantage (as the conditional probability goes from each product to the other). This probability is calculated for successfully exported products only, ${ }^{3}$ for all countries in the world at any year (Hidalgo et al. 2007). ${ }^{4}$ The presentation of the space (Figure 2) shows that this space is heterogeneous, a core periphery with a densely connected structure to which two types of products are connected: the first, the peripheral products that are only weakly connected to the core, such as oil; second, groupings of peripheral products that, despite being strongly connected to each other, are weakly connected to the core, such as the dense, compact, green garment cluster to the left of the network. Because garments and textiles require different types of productive knowledge - that is, the proficiencies required to competitively make textiles are quite distinct from those required to make garments - these two belong to two distinct communities in the product space, despite being very closely connected in the value chain, hence the divergence of vertical chains of operation, forward and backward linkages, or input-output table concepts to that of the product space. The core is located in the centre of the network and is made up of the densely connected blue product cluster of machinery and other capital-intensive goods. The light turquoise cluster of electronics in the lower right corner is also strongly connected to the core.

3 That is, it is calculated for all exports with a revealed comparative advantage (RCA) greater than 1. RCA is an index used to calculate the relative advantage or disadvantage a country has in the export of a certain good. A more technical definition of RCA can be found in endnote 9 .

4 Proximity is the inverse measure of distance between goods $\mathrm{i}$ and $\mathrm{j}$ in year $\mathrm{t}$ and equals $\phi_{\mathrm{i}, \mathrm{j}, \mathrm{t}}=$ $\min \left\{P\left(x_{i, t} \mid x_{j, t}\right), P\left(x_{j, t} \mid x_{i, t}\right)\right\}$ where for any country c $x_{i, c, t}=\left\{\begin{array}{l}1 \text { if } \mathrm{RCA}_{i, j, t}>1 \\ 0 \text { otherwise }\end{array}\right.$. 


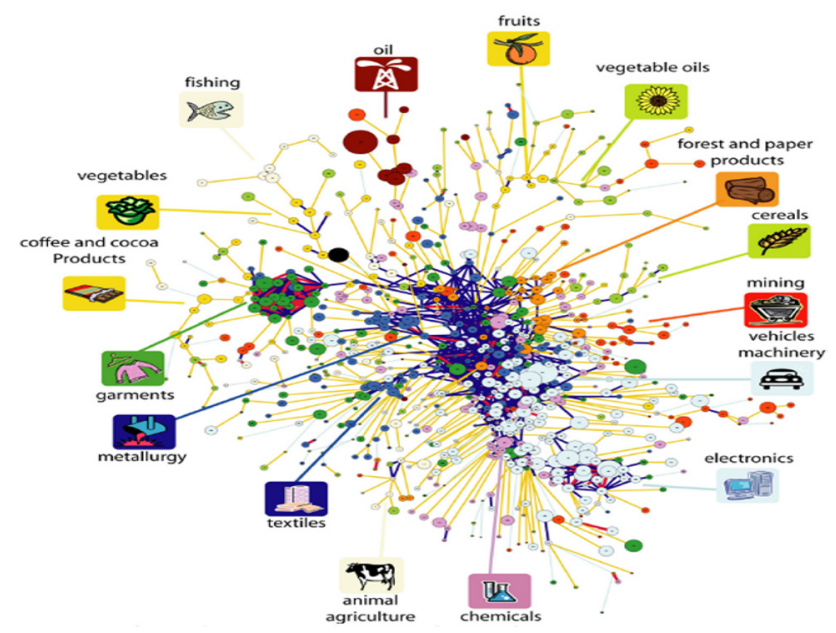

Figure 2: The global product space and Leamer clusters (2006-2008).

Note: 1) Each node is a product, 2) node size reflects product's size in world trade, 3) proximity as explained above is expressed by the colour-coded links between pairs of products according to linkage strength, 4) specifically light blue links indicate proximity less than 0.4 , beige links proximity of $0.40-0.55$, dark blue proximity of $0.55-0.65$ and finally a red link depicts proximity greater than 0.65 . Hierarchically clustered proximity matrix represents the 775 SITC-4 product classes exported in the 1998-2000 period. This network representation of the product space is laid out using a force spring algorithm and is retouched by hand.

Source: Hidalgo et al. (2007, Figure 1, p. 8).

\subsection{Complexity and Connectedness}

The overall complexity index of a country (ECI) is the joint outcome of the different levels of complexity of every product that that country exports. At the product level, a product's complexity reveals the amount of productive knowledge that product requires. Complexity and connectedness go hand in hand, that is, the more complex the community, the more connected it is (Figure 3). As Hausmann (2014) put it, as countries diversify into more complex products, they also increase their opportunities for further diversification, which is referred to as the "opportunity value" of their location in the space. Machinery and the various chemicals communities are by far the most complex communities and also the most connected. Their connectedness can be seen in the map of the product space (Figure 2), as these communities are located in the most central and dense areas of the network. Oil, on the other hand, is the least connected and also one of the least complex. Since the sizes of the bubbles representing the communities indicate their share in world trade, it is easy to visualise which communities offer greater 


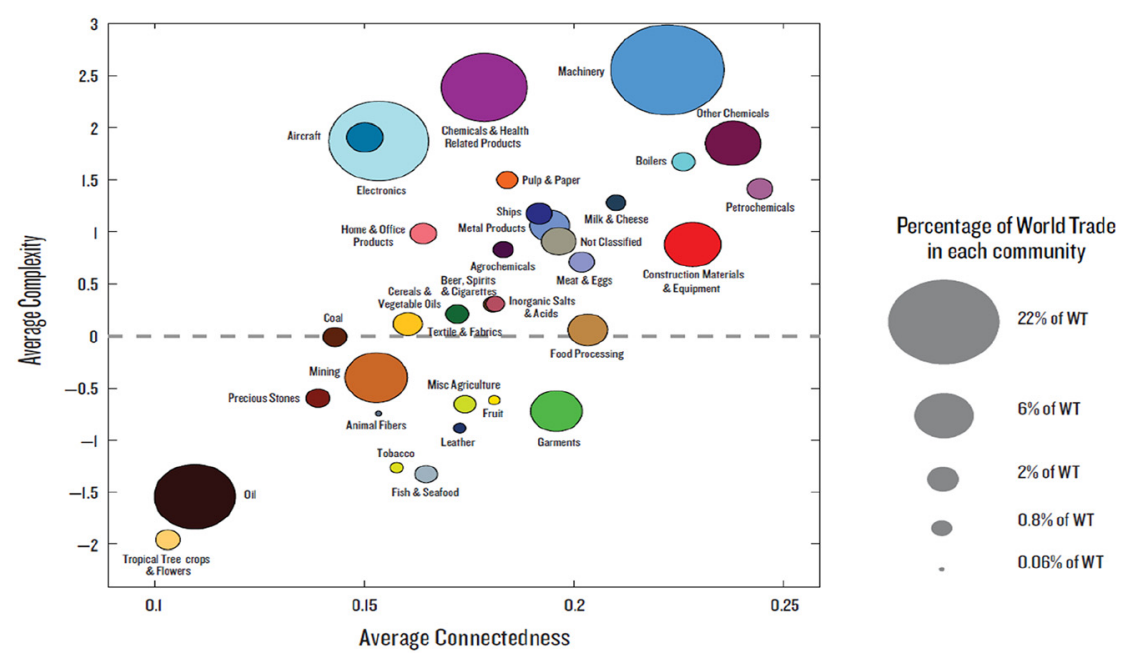

Figure 3: Community characteristics.

Source: Hausmann, Ricardo, César A.Hidalgo, Sebastián Bustos, Michele Coscia, Alexander Simoes, and Muhammed A. Yildirim., The Atlas of Economic Complexity (2014, Figure 5.3, p. 54).

access to global demand and international markets. Machinery and electronics represent the top in world trade.

\subsection{Egypt and Tunisia in the Product Space}

\subsubsection{The Current State}

Table 2 gives the aggregated structure of Egyptian and Tunisian exports. Figure 4a$\mathrm{d}$ depict in more detail the structural differences between the two countries in 2014 at the product level. Although both have a relatively large presence in the hydrocarbon sector, as established above, Egypt has a relatively larger one. The hydrocarbon sector is exclusively linked to itself and to the core with beige coloured lines (Figure 2), and therefore poorly connected to the rest of the space, as also shown in Figure 3 above. That is, if you export oil, you are less likely to export other products, or, in general, at least it is more of a challenge to do so (Hausmann et al. 2014). This is reflected in the current export structure of the two countries.

Other than mineral products (8.9), which come only in fourth place (Table 2), Tunisia has a significant export presence in (i) electronics and machinery sectors (29.7, blue), (ii) textiles (18.94, the dark green dots and rectangles), (iii) vegetables (10.3, purple) and (iv) chemicals (5.6, light blue). The largest share of exported products for Tunisia is comprised of wires, cable and other insulated electric 
Table 2: Sectoral shares in total merchandise exports, 2014.

\begin{tabular}{lrr}
\hline & Egypt & Tunisia \\
\hline Mineral products & 25.99 & 8.91 \\
Textiles & 13.36 & 18.94 \\
Vegetable products & 12.49 & 10.31 \\
Chemicals \& allied industries & 8.62 & 5.59 \\
Metals & 6.70 & 3.60 \\
Machinery/electronics & 8.23 & 29.68 \\
Plastics / rubbers & 5.84 & 2.75 \\
Foodstuffs & 5.40 & 2.30 \\
Stone / glass & 6.27 & 0.79 \\
Miscellaneous & 2.04 & 5.17 \\
Wood \& wood products & 1.88 & 1.64 \\
Animal \& animal products & 1.92 & 1.50 \\
Raw hides, skins, leather, and furs & 0.68 & 1.03 \\
Transportation & 0.53 & 5.02 \\
Footwear / headgear & 0.04 & 2.76 \\
\hline
\end{tabular}

Source: Author calculations from two-digit level Ho (1988/1992) data, Atlas of Economic Complexity (Center for International Development at Harvard University 2016). Minerals include chapters 25-27.

conductors (the largest blue dot in 4b, and the rectangle in $4 \mathrm{~d}$ ), ${ }^{5}$ which explains an RCA (17.1) four times as large as that of Egypt's for that product. Tunisia's machinery/electronics sector exports are nearly as large as Egypt's entire exports of mineral products ${ }^{6}$ (28 vs. $34 \%$ of total exports, Table 2 ).

The size of Egypt's non-mineral trade, on the other hand, is relatively small (74\%). Egypt has a relatively large presence, first in the textiles/garments community (13.4), followed by vegetables (12.5) then the chemicals community (8.62) within which the plastics and rubber communities lie (dark and light pink dots and rectangles in $4 \mathrm{a}$ and $\mathrm{d}$ ), the latter more or less derivatives of hydrocarbon. The greater presence of dark brown and yellow dots and rectangles illustrates that many of Egypt's exports rely heavily on natural resources as well as primary agricultural products, notably so when compared to Tunisia (see also El-Haddad 2015a for detailed structural transformation trends in Egypt over the past 60 years).

The many nodes in $4 a$ are approximately of equal size and equally sparse with no clear clusters, indicating that Egypt is exporting competitively in a larger number of sectors, albeit with limited specialisation, in contrast to Tunisia. The latter is clearly better specialised in the few sectors indicated above. The many nodes Tunisia has in

5 The other three significant exported sectors are switches, relays, fuses, surge suppressors, plugs, sockets, lamp holders, electric motor generators, and monitors and projectors. The largest transport sector items are parts and accessories of motor vehicles.

6 Tunisia's hydrocarbon exports amount to approximately $7.4 \%$ of all exports. 


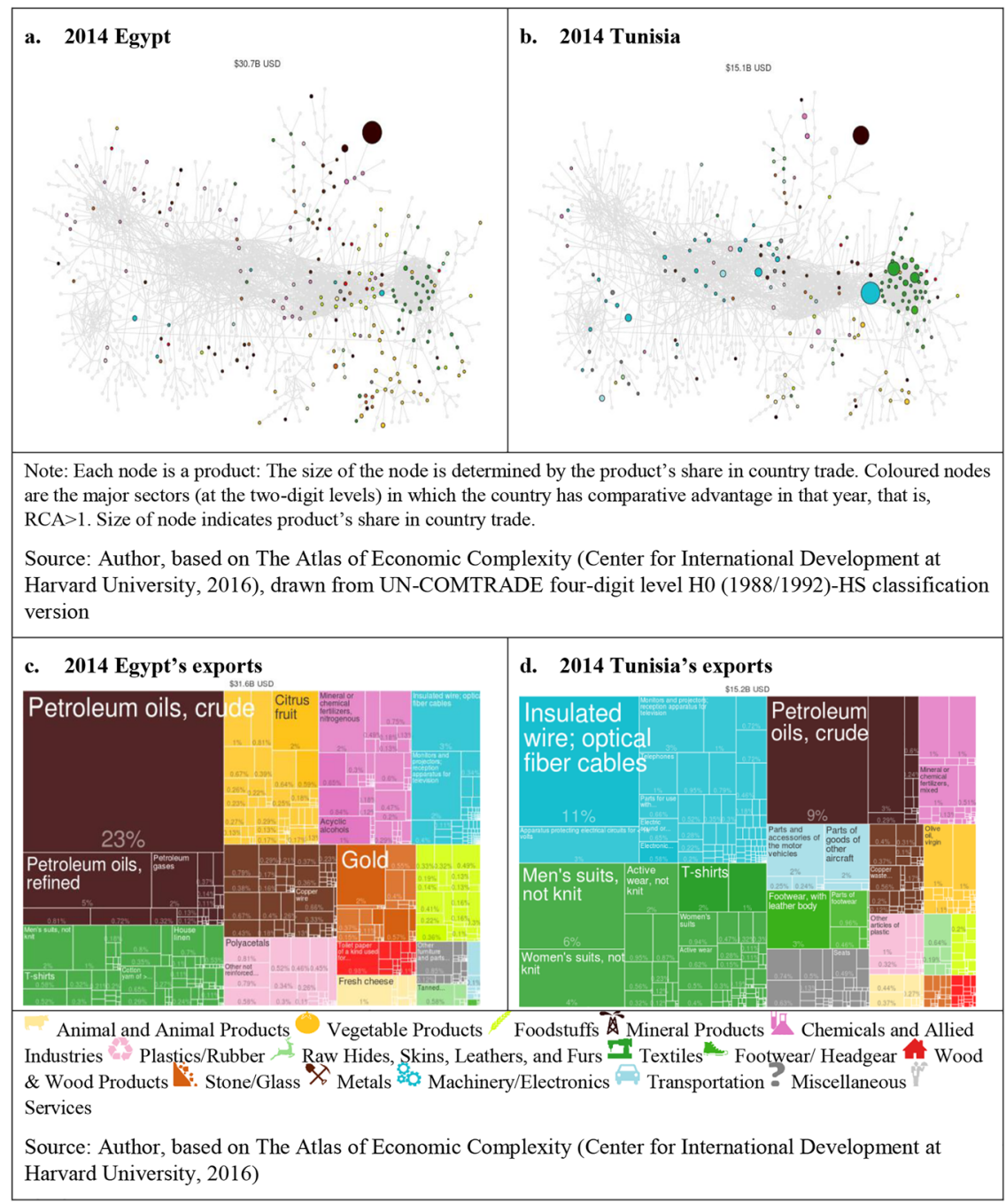

Figure 4: Egypt and Tunisia in the product space (2014).

the electronics sector - and the few it has in machinery - are bigger, indicating greater specialisation for a number of its export products other than oil, compared to Egypt.

\subsubsection{Structural Transformation Over Time}

Structural transformation here refers to persistent long-term shifts in the sectoral composition of the economy away from primary sectors, such as agriculture, 
hydrocarbons and mining, towards manufacturing or high-value services, or, alternatively, the move away from light to heavy industries or from labour- to capitalintensive sectors. Egypt has experienced some - albeit limited - structural transformation during the past 20 years (Figure 5). This transformation has seen hydrocarbon exports increase in absolute terms, but also the emergence of some other more processed sectors.

Some growth in exports of mineral products and chemical fertilisers in the chemicals cluster - building on the weak links with oil (the largest dark pink dot) took place as well as growth in copper plates, sheets and strips (light brown dot to the left of the space) and in gold, both unwrought and semi-manufactured (the orange dot towards the lower right corner). Whilst Egypt has managed to reduce the share of primary products over time, these products still occupy just under half of all Egyptian exports of tradable goods (the share of mineral, vegetable and animal products combined has dropped from 58\% in 1995 to 45\% in 2014, see also Table 2).

Tunisia, on the other hand, exhibited better structural transformation during the same 20-year period. This transformation is reflected in the relative shrinkage in its major light industry exports, garments and textiles exports (the green dots); and to a lesser extent in olive oil (yellow dot at the far lower right corner for 1995); and a growth in metallurgy (light brown) and other dispersed machinery (dark blue); and electronics sectors (light blue, Figure 6). Overall, it has reduced the share of its natural resources and primary agricultural products from 20 to $18 \%$ of all exports, which is less than half the level in Egypt's basket (40\% of it).

\subsubsection{Location Opportunities: Cross-Country Comparisons}

According to Hausmann et al. (2011), diversification of a country into much more sophisticated export activities is inhibited because these considerably more sophisticated activities are still very far from the established production structures of the country, and thus require a completely new set of capabilities. Over time, as countries produce increasingly sophisticated products, their set of existing capabilities evolves, which allows them to then increase their sophistication levels. Therefore, it is not of great surprise that, for the time being, the two countries have limited sophistication levels and little economic complexity (Figure A4), which is a reflection of their existing capabilities associated with their most recent production/export structures. Tunisia, which recently has had a smaller oil sector but larger garments and textiles sector, managed to diversify into more complex metals and then, later into closely connected electronics. The larger hydrocarbon sector has partly made export sophistication more of a challenge for Egypt. This is because the conditional probability of exporting any 


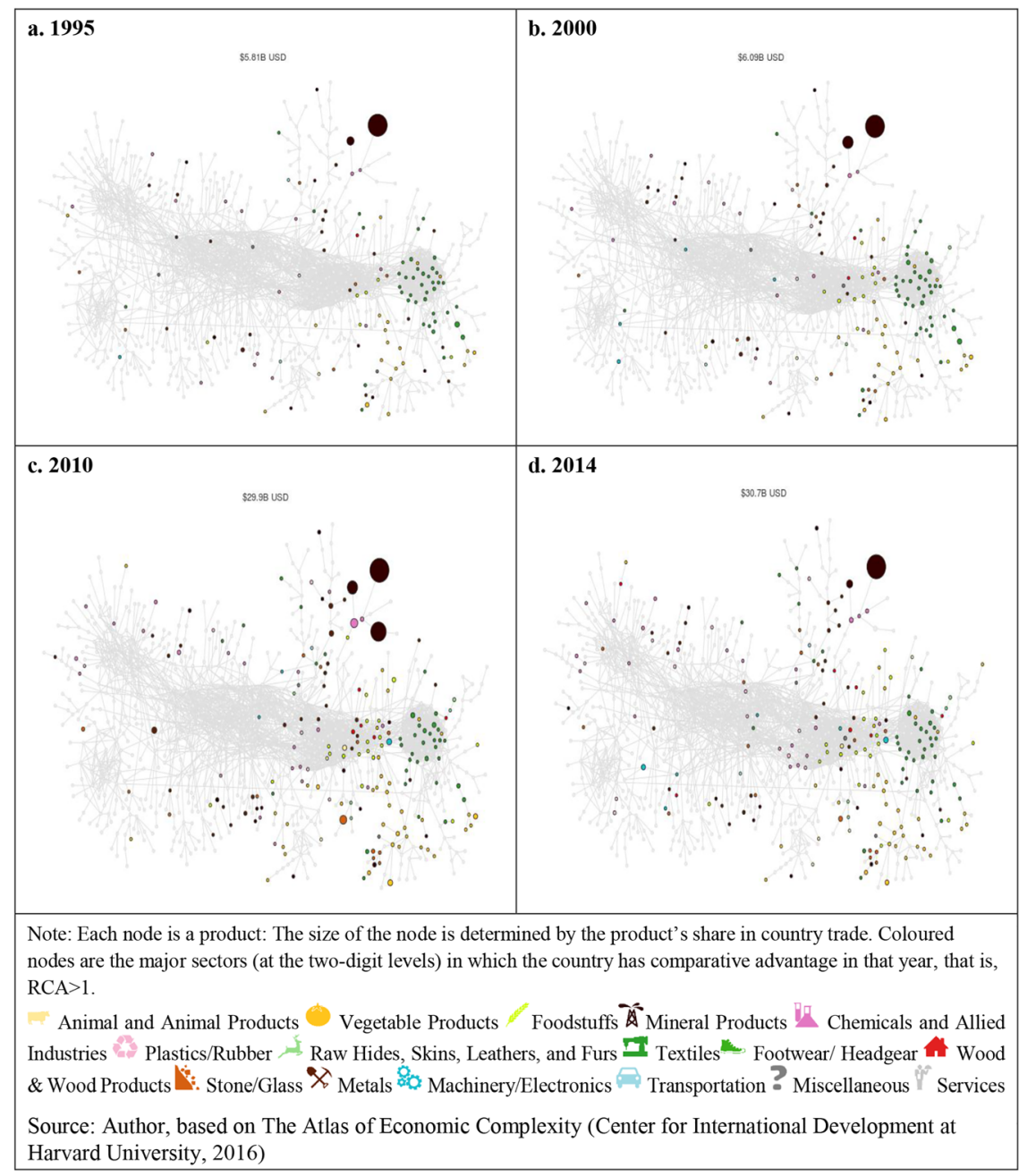

Figure 5: Evolution of Egypt's position in the product space.

one sophisticated product declines when oil is exported as well, ${ }^{7}$ therefore the distances between these two products increase, which, in turn, limits the possibilities for

7 Note that this methodology works out its results based on observed export trends across the world. Those trends made it clear that the more oil produced and exported in a country, the less likely other more sophisticated products would be produced and exported. Economic theory has explained this with Dutch disease, which, in the presence of rents, including oil rents, makes the tradable sector of countries less profitable, diverting the production structure of the economy towards more non-tradable activities (of which sophisticated export products are a part). 


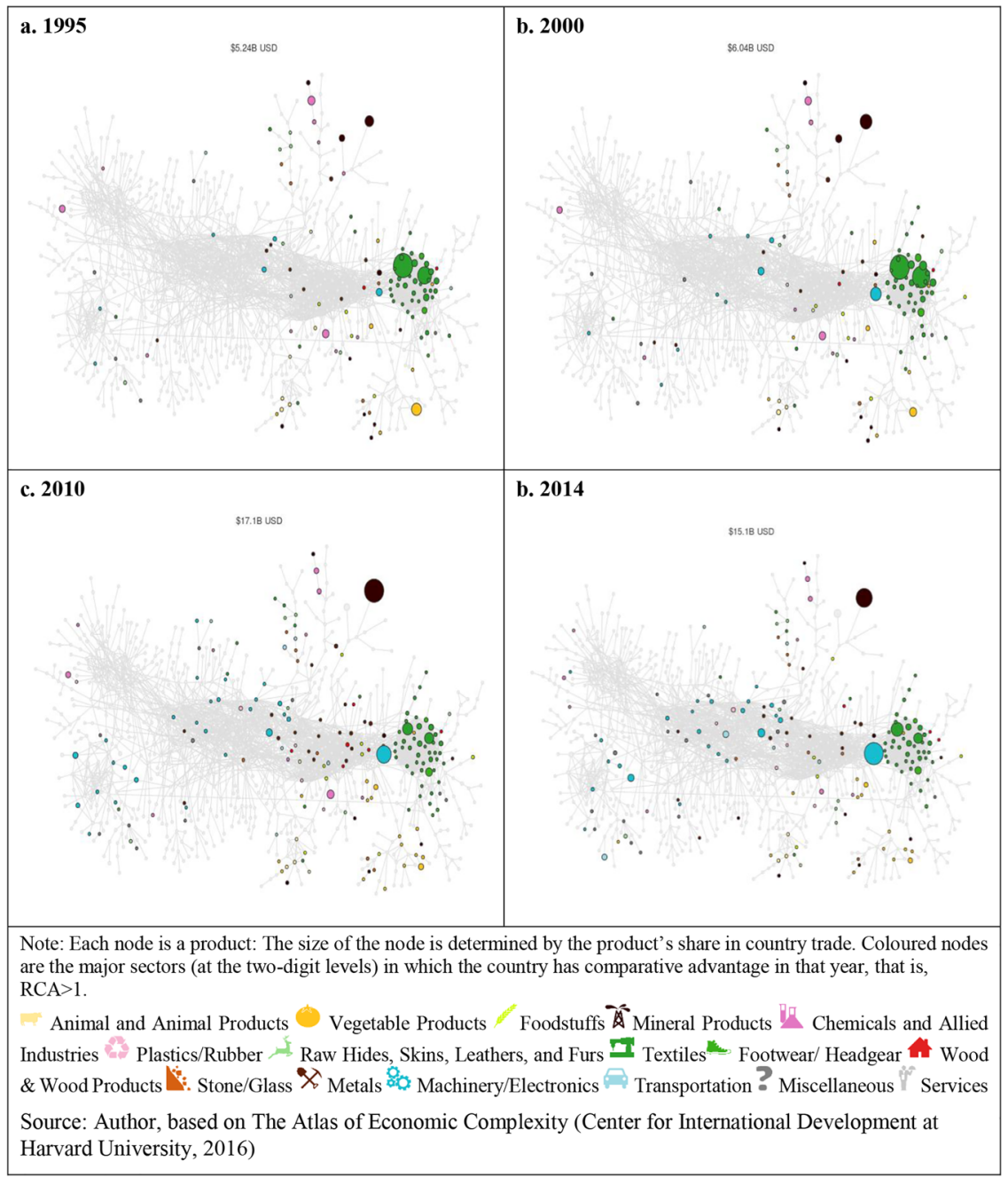

Figure 6: Tunisia in the product space.

sophistication. The negative relation between distance and sophistication is illuminated below, where the concept of opportunity value is introduced. Countries move towards nearby activities over time; it is rare to see big jumps across the product space (Hausmann and Klinger 2007; Hidalgo et al. 2007).

What exactly are the two countries' prospects for greater sophistication? Hausmann et al. (2011) construct a measure they call opportunity value (OV). OV is a unique measure for each country that represents the benefit of a country's location in the product space. Specifically, it measures how many other more sophisticated products are near a country's current set of productive capabilities. 
In brief, it is a very simple measure that increases as the distance to relatively more sophisticated products that the country is not currently exporting decreases. It also increases as the number of relatively more sophisticated products the country is not currently exporting increases (see Annex A2 for OV definition).

In other words, OV depends on two parts: (1) an opportunity part, represented by products a country has yet to produce and export that are more sophisticated than current products; and (2) a capability part, which is often described as having more available letters in a scrabble game; this allows the player to put together more words, that is, countries have the technical ability to produce more sophisticated products, which is represented by the distance in the equation in Derivation A2. The final value of the OV indicator thus depends on the interaction of these two parts. Hence, $\mathrm{OV}$ is a strong predictor of a country's future potential of moving into new, more sophisticated activities over time.

Figure 7 is the cross-country scatter plot of OV against GDP per capita. The figure shows the following. First, despite Tunisia's higher Economic Complexity Index, after controlling for initial income and growth in natural-resource exports, Egypt has a more favourable OV compared to that of Tunisia, given its level of real GDP per capita. This seemingly puzzling result is explained by the fact that countries which have a larger number of more sophisticated, "unsuccessfully exported" 8,9 products

8 "Unsuccessfully exported" refers to products that are either entirely unexported or exported with no comparative advantage (i.e. with RCA $<1$ ). See the following endnote for a definition of RCA. 9 More accurately, this refers to either entirely non-exported products or exports with no revealed comparative advantage for which RCA $<1$. RCA is an index used to calculate the relative advantage or disadvantage a country has in the export of a certain good. We use Balassa's definition of RCA, which says that a country has RCA in a product if it exports more than its "fair share", or a share that is equal to or greater than the share of total world trade that the product represents. For example, in 2010, soybeans represented $0.35 \%$ of world trade, with exports of $\$ 42$ billion. Of this total, Brazil exported nearly $\$ 11$ billion, and since Brazil's total exports for that year were $\$ 140$ billion, soybeans accounted for $7.8 \%$ of Brazil's exports. Because 7.8/0.35 = 22, Brazil exports 22 times its "fair share" of soybean exports, so we can say that Brazil has a high RCA in soybeans. Formally, if Xcp represents the export of product $\boldsymbol{p}$ by country $\boldsymbol{c}$, we can express the RCA that country $\boldsymbol{c}$ has in product $\boldsymbol{p}$ as

$\mathrm{RCA}_{c p}=\frac{X_{c p} / \sum_{c} X_{c p}}{\sum_{p} X_{c p} / \sum_{c} \sum_{p} X_{c p}}$

Type equation here.We can use this measure to construct a matrix that connects each country to the products that it makes. $M_{c p}$ is the matrix summarising which country makes what, where rows represent different countries and columns represents different products. It is used to construct the product space and our measurements of economic complexity for countries and products. Entries in the matrix are 1 if country $\boldsymbol{c}$ exports product $\boldsymbol{p}$ with RCA greater than 1, otherwise 0 . Formally, we define this as the $M_{c p}$ matrix, where

$M_{c p}= \begin{cases}1 & \text { RCA }_{c p} \geq 1 \\ 0 & \text { otherwise }\end{cases}$

(Hausmann, Hidalgo et al., 2014). 
will have a greater OV, as they still have a rich "unexploited" neighbourhood of highly connected and/or complex products. In other words, they have not yet fulfilled much of their full potential.

Because of its greater degree of specialisation, Tunisia has a larger number of unsuccessfully exported products compared to Egypt: 1006 and 954, respectively (Table 4). There are two elements that explain Egypt's higher OV. ${ }^{10}$ First, with a higher ECI value, Tunisia produces overall more complex products compared to Egypt. But the more a country produces complex products, the less complexity that remains; more accurately, this means that fewer new, potentially more complex products remain unexploited. This pushes the OV down. Indeed, Tunisia is left with a larger number of unsuccessfully exported products but, of those, only 695 are more complex than Tunisia's average level of complexity (i.e. its ECI level). By contrast, Egypt has 726. This implies that, given their different positions in 2015, Egypt has a better chance of diversifying its current export basket. Put differently, Egypt has a greater unfulfilled potential for diversifying into more sophisticated products.

Second, Tunisia better exhausted its nearby complex products, whereas Egypt has not (yet) done so. But the more a country produces in its neighbourhood, the greater the remaining average unexploited distance is. ${ }^{11}$ Tunisia's remaining average distance is greater than Egypt's 0.82 (Table 3). This drives down the OV as well.

The second message of Figure 7 is that both countries have relatively high levels of connectedness for their levels of GDP per capita, compared to other oil-exporting countries from the region and elsewhere. Compare, for example, Algeria and Iraq, which both show clear signs of oil curse: higher levels of GDP per capita and much lower OV. This follows from much larger distances to their very large number of more sophisticated, unsuccessfully exported products (1049 for Algeria and 1190 for Iraq). In other words, their more sophisticated products are very far from the countries' current set of productive capabilities.

Finally, the results are mixed when looking at some high-growth economies. Egypt has greater opportunities than Indonesia, despite having identical incomes per capita and shares of hydrocarbon exports. The number of more sophisticated, unsuccessful exports is considerably larger for Indonesia than either Egypt or Tunisia, but its average distance is greater than Egypt's (Table 3). With nearly half of Egypt's income per capita and a much higher OV (3.59), India has considerable value in its location. Its set of productive knowledge lies closer to the fewer, more sophisticated,

10 It lies above the regression line of GDP per capita growth and the Economic Complexity Index after controlling for initial income and growth in natural resource exports (Figure A6 in the Annex). 11 Average distance for the more complex, unsuccessfully exported products. 


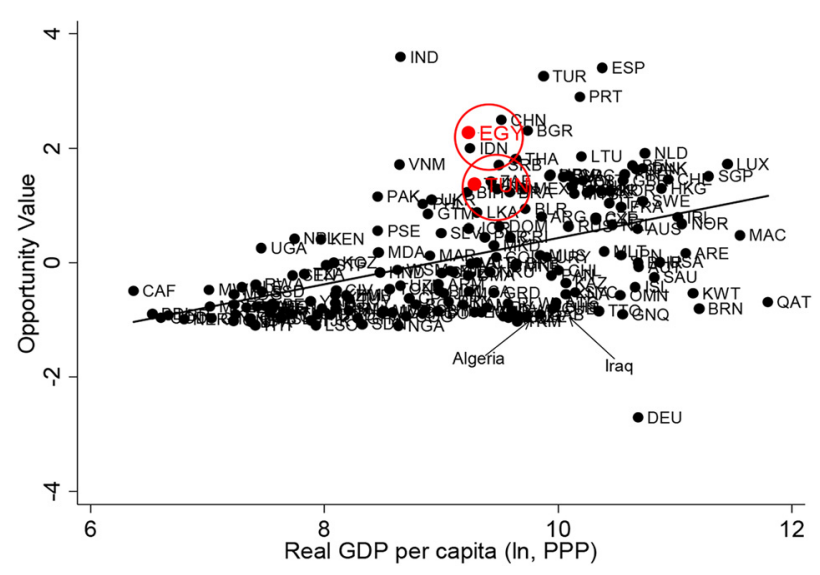

Figure 7: Opportunity value and GDP per capita, 2015 (all countries). Note: $\mathrm{EGY}=$ Egypt, TUN $=$ Tunisia, DZA = Algeria.

Source: Author's calculations based on the Atlas of Economic Complexity data (Center for International Development at Harvard University, 2016) and World Bank (2016).

unsuccessfully exported products (621). Vietnam is another remarkable example: It has just half of Tunisia's income per capita but a higher OV on account of its relatively more advanced, accumulated productive knowledge. Pakistan also has relatively advanced prospects. Similarly, Bosnia and Ukraine also have good prospects. But these are all countries with no - or very limited - exports of hydrocarbons, particularly in their crude form, compared to Egypt and, to a lesser extent, Tunisia. Therefore, they are more easily able to be relatively connected to the rest of the product space.

Figure 8 conveys the same messages. It shows both countries at another country level comparison pertaining to their relative position in the product space. The figure plots opportunity value against economic complexity. Two types of countries are not rewarded for their overall level of complexity, namely: a) those that have very low levels of complexity because they have limited accumulated productive knowledge and so few products nearby, thus limiting their ability to diversify further (in technical terms, they have greater average distance to their more sophisticated, unsuccessfully exported products; and b) countries with very high hoarded productive knowledge, such as Japan, the United States and Germany - the latter an extreme outlier with very little opportunity value, in fact, the least of all countries. This is so because they have already exhausted all opportunities and already occupy a large fraction of the better part of the product space. In technical terms, they have fewer, more sophisticated, unsuccessfully exported products. Most notably, Germany has the fewest products in the world - which are more sophisticated than the country's 


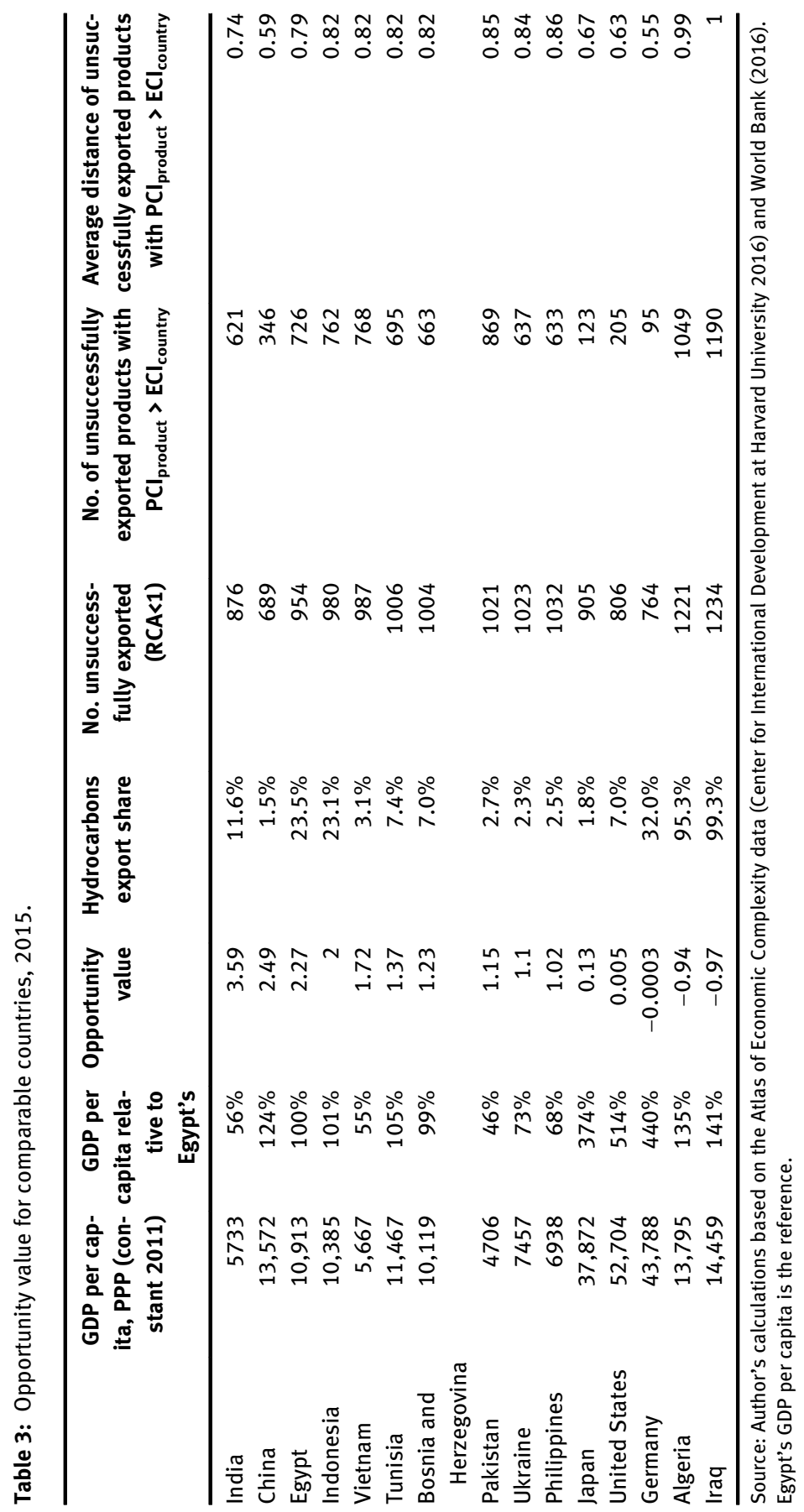


current complexity level - that it does not yet successfully export (95, see Table 3). ${ }^{12}$ This decreases its OV markedly, which is unable to offset the country's very low average distance, which is also the smallest in the world, a reflection of the largest accumulated knowledge that exists worldwide.

For countries in the middle section, there is a positive relation between complexity and opportunity value. Tunisia and Egypt fall above the line indicating that both are in a good position to achieve diversification, complexity and, in turn, economic growth.

\section{Product Space Sector Possibilities for Egyptian and Tunisian Future Exports}

This section presents the identified sectors for future production based on the Product Space Methodology. It also contrasts these results with those for two more strategies. The first is on the other end of the spectrum from the Product Space Methodology, which is a strategy pushing for much more sophistication. The second is in the middle of the spectrum and places significant weight on current trade trends in manufactured products.

\subsection{Product Feasibility}

Figure 8a (Egypt) and 8b (Tunisia) show clear trade-offs. The $x$-axis gives the distance of each non- or weakly-exported product from Egypt's (Tunisia's) current position in the product space (please refer to endnotes 4 and 9). The more to the left, the closer the non-exported product is to Egypt's (Tunisia's) current stock of productive knowledge. The $y$-axis in Figures 8a and b measures the level of complexity of the product. The ideal choice is to pick products at the very corner of the upper left quadrant (Hausmann et al. 2005). These are the products with the highest levels of complexity, which are located as close as possible to the country's current set of capabilities. For Egypt, at the lower end are dairy products such as eggs and cream, that is, products from live animals. Cereal, ice cream and baked products such as bread and biscuits follow - more highly processed foods. In addition, pipes and tubes of iron and steel and some more complex plastic articles (e.g. plates) were followed by medicaments and then other articles of iron or steel. Farther away, hence

12 Iraq, on the other hand, lies at the other end of the spectrum to Germany with: 1) the highest number for unsuccessfully exported products as well as the highest numbers for more sophisticated, unsuccessfully exported products and; 2) the greatest distance and average distance (0.997) to its more sophisticated, unsuccessfully exported products. 


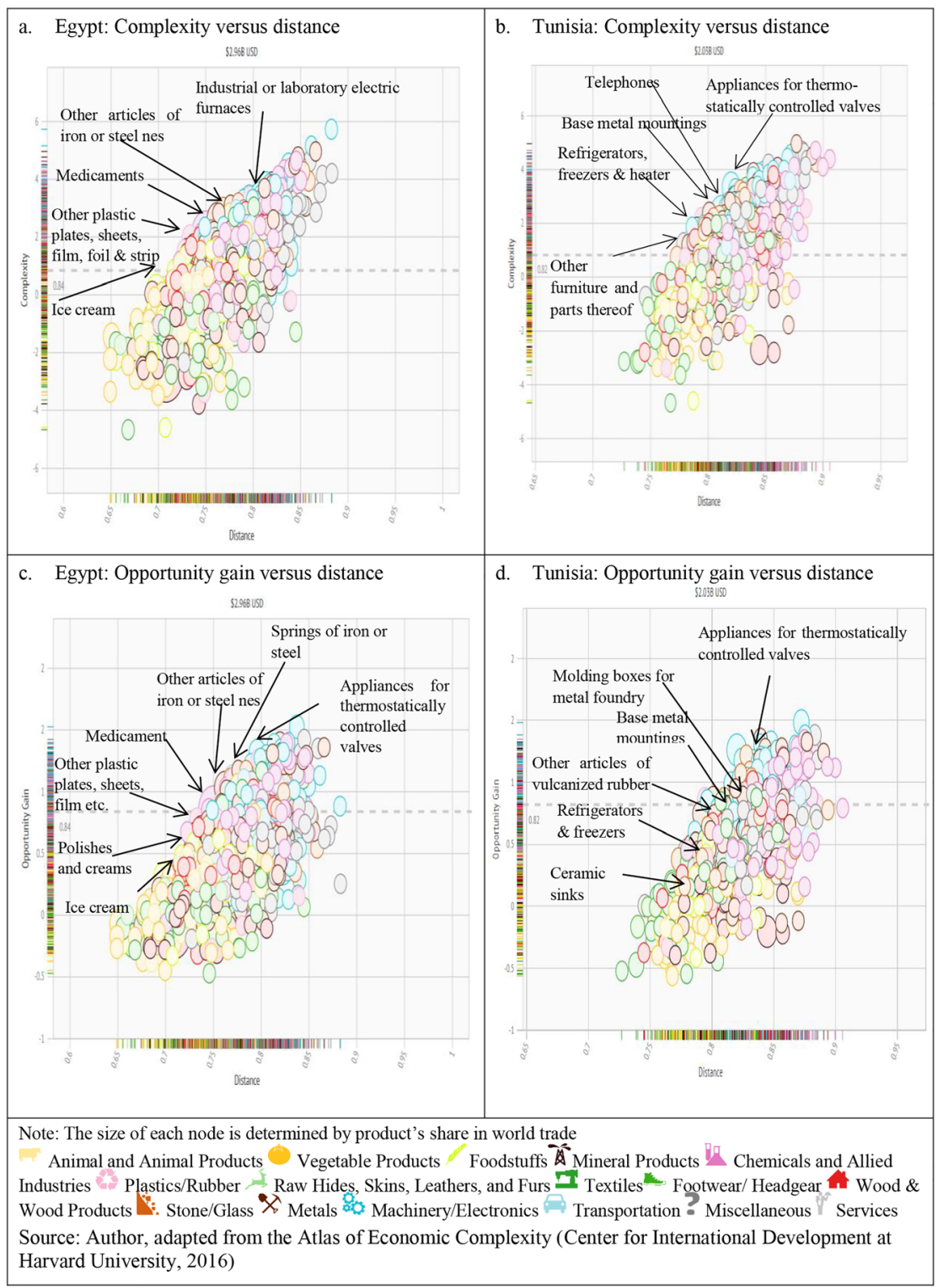

Figure 8: Product feasibility: complexity and opportunity gain (2014).

more sophisticated, are industrial electric furnaces. For Tunisia, the feasible products that are an upgrade in terms of complexity are waste of manmade fibre, ceramic sinks, furniture, refrigerators and freezers, base metal mountings, telephones and other appliances for thermostat-controlled valves, yet the more distant, the more 
complex. It is clear that Tunisia has more low-hanging fruit in electronics compared to Egypt, where the advantages are in the chemicals sector.

Another trade-off also exists between proximity or distance and opportunity gain (OG) (Figures 12c and d). A product can be close to the current set of a country's capabilities but adds very little value to the country's connectedness in the product space and, in turn, to its sophisticated diversification prospects for the future. If the new product is in a dense part of the product space, then producing it would create capabilities with significant value for other new and complex products, and vice versa. OG is thus at the level of the product, in contrast to OV, which is at the level of countries. Here there is also a negative relation between the $\mathrm{OG}^{13}$ of a product and its distance. ${ }^{14}$ Again, OG varies, for example between "low" (agricultural products such as cucumber and bread), "moderate" (ice cream) and "high" (appliances for thermostat-controlled valves). For Tunisia, in the upper left quadrant, it rises from textiles (the green dots) to ceramic sinks (metals sector) to refrigerators and then to appliances for thermostatcontrolled valves (electronics). The latter are products that provide more OGs but are farther away from Tunisia's current set of productive capabilities.

\subsection{Product Space Methodology Results}

The PSM results are presented in Tables A2 and A3, which give the first 20 upmarket products for Egypt and Tunisia. These products meet each of the following criteria: a) they lie above the regression line of the PCI on distance (red dots in Figure 9a and b) to ensure greater complexity for the same distance (additionally, they have a PCI that exceeds the average ECI level of the relevant country, ${ }^{15}$ so adding them would increase each country's current level of economic complexity); b) they lie above the regression line of OG on distance and their OG is positive (red dots in Figure 9c and d), so they are able to move the country into parts of the product space that are more connected, thereby leading to more diversification in the future; $c$ ) the respective country does not produce them with a comparative advantage,

13 "Complexity outlook gain" (COG) is used to calculate the potential benefit to a country if it were to move towards a particular new product. It is calculated as the change in complexity outlook that would come about from developing that product. "Opportunity gain" quantifies the contribution of a new product in terms of opening the doors to more - and more complex - products. Formally, this is the opportunity gain given as (Hausmann, Hidalgo et al., 2014): Opportunity Gain $=\operatorname{COG}_{c p}\left[\sum_{p^{\prime}} \frac{\varnothing_{p, p^{\prime}}}{\sum_{p^{\prime \prime}} \varnothing_{p^{\prime \prime}, p^{\prime}}}\left(1-M_{c p^{\prime}}\right) P C I_{p^{\prime}}\right]-\left(1-d_{c p}\right) \mathrm{PCI}_{p}$.

14 This confirms and represents another way of looking at the positive results between opportunity value and complexity we saw earlier in Figure 6.

15 Therefore greater than -0.22 for Egypt and 0.1 for Tunisia. 
that is, products should have an $\mathrm{RCA}<1$; and d) they should be no farther than the average distance to ensure proximity to the country's productive knowledge.

The results in Tables A2 and A3 in the Annex A3 are ordered by distance. As the methodology would suggest, top products for Egypt are mostly agricultural products the first ones are live animals, so very simple animal products $(\mathrm{PCI}=-017)$ - followed by simple wooden pulp products such as paper (-0.06), and then metals and minerals (e.g. salt and sulphur). Only further down do we find food processing, such as water beverages, vinegar and cereals, very basic plastics as well as more complex metal, stone and glass (classified in the mineral products group) as well as textiles and clothing. Beyond the top 20 products at the very end are high-value chemicals as well as machinery and electronics. Since Tunisia is more sophisticated, the top products are, in relative terms, slightly more complex in the chemicals area (containers and bobbins), and there are more sophisticated wooden products (e.g. broom handles and wickerwork), some products with low levels of complexity from the highly manufactured goods area, such as furniture $(\mathrm{PCI}=0.95)$, and then food processing and textiles and clothing. These results will be contrasted in the following section using a more invasive approach.

\subsection{Strategic Bets: More Active Industrial Policy}

Inward-looking development strategies dominated much of the thinking of several newly-independent countries, such as India and the Maghreb countries, in the second half of the twentieth century. In terms of industrial policy, such an orientation results in the adoption of an import substitution industrial strategy. It also means a desire to quickly move away from light industries, such as food processing and clothing, to more sophisticated, capital-intensive, heavy industries, such as machinery and iron and steel. As a result, in both Egypt and Tunisia, the surplus generated from agriculture has been used to finance industrial development into heavy industry (El-Haddad 2010). In the jargon of the PSM, this industrial policy orientation is referred to as Strategic Bets. Strategic Bets is a strategy that accentuates more sophisticated sectors, which therefore provide also greater $\mathrm{OG}$, despite the larger distance. These industries will push economic growth and achieve more diversification and urban job-creation (Hausmann, Hidalgo et al., 2014). ${ }^{16}$

16 There is no contradiction here. Still, more sophisticated products are less labour-intensive compared to less sophisticated products. However, the point is that the small amounts of employment that more sophisticated products actually create will be in urban areas as opposed to rural areas. 


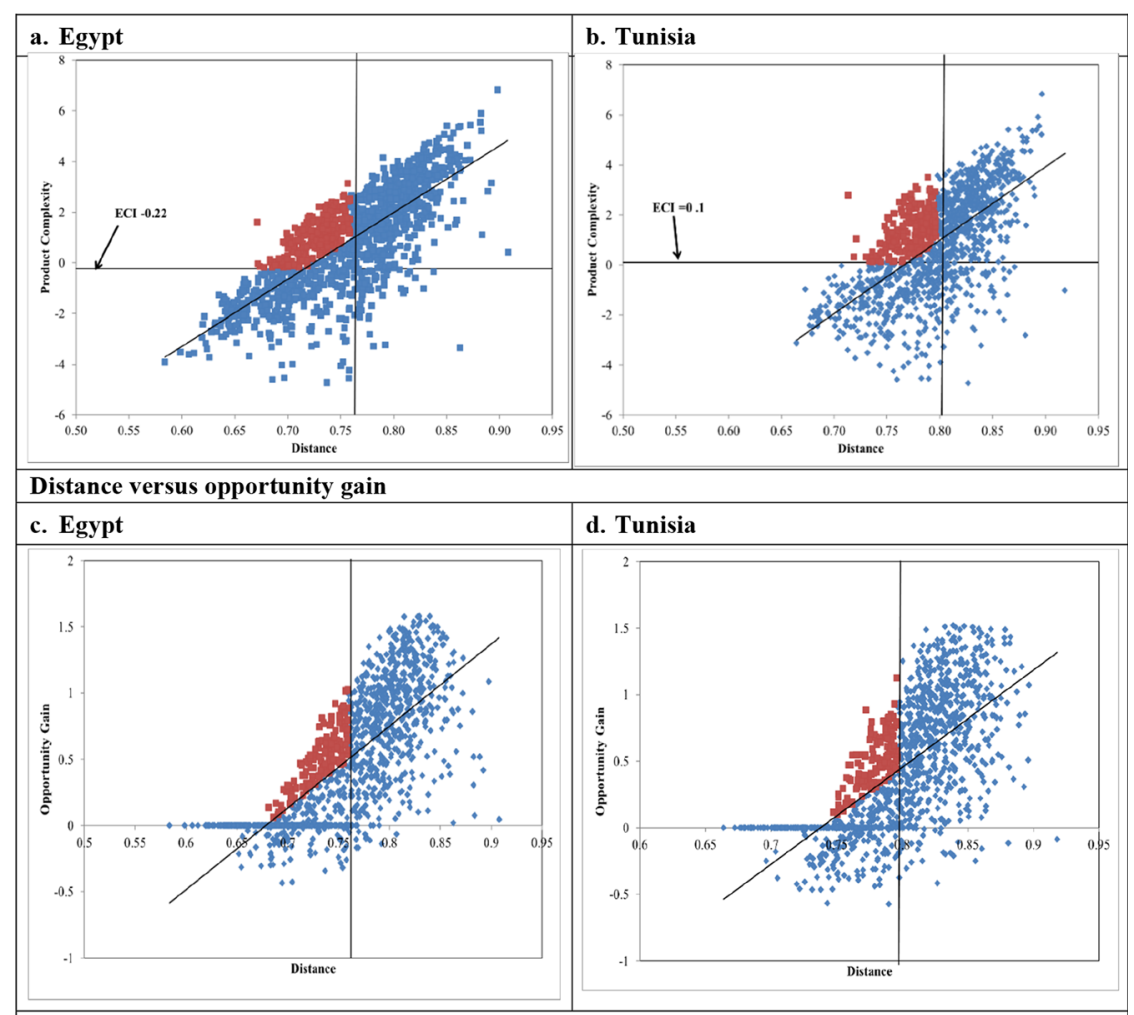

Figure 9: Distance versus product complexity and opportunity gain regressions. Source: Author's calculation based on Atlas of Economic Complexity data (Center for International Development at Harvard University, 2016).

In line with the Strategic Bets strategy, instead of focussing on proximity, our countries would focus on giving a greater weight to product complexity and OG and less to distance. Tables A4 and A5 show the results for products in the top 40\% in terms of both complexity and OG, with a distance that is as much as $80 \%$ or more away from the respective country's average distance. The results are, at the very end of the spectrum, led by highly complex manufactured metals, machinery, equipment, electronics and chemicals (Tables A4 and A5). These are also the results that are repeated most often (141, 181 for Egypt and Tunisia respectively, Table 4). However, there is a drawback, especially for countries with such high (youth) unemployment rates, such as Egypt and Tunisia (ILO 2020). These sectors are mostly less labour-intensive and require high-skilled workers. If workers are quickly moved out of labour-intensive light-manufacturing sectors - agricultural products, garments and food processing - then the workforce may be moved into 
unemployment or into low-productivity informal sectors. The tradeoff - better jobs versus more jobs, or jobless versus penniless growth - is quite apparent here.

\subsection{Forward-looking Strategy: Trends in International Markets}

There are a number of criticisms directed at the PSM, which are dealt with in some details in Section 5 below. Among these is the limited ability of trade classifications to reflect market size and trade policies (Radosevic 2017, in Altenburg, Kleinz, and Lütkenhorst 2016). The variation introduced in this section is mainly directed at the limitation of the approach regarding market size.

In common with the PSM, the Strategic Bets strategy - also a variant of the Product Space Methodology - does not consider the effect of world trade on the future viability of these sectors. There is no doubt that developed countries have increasingly lost market share to developing countries. Thus, it is important to take international trade trends into account when identifying upmarket sectors. Taking into account the significance of every product in world trade is indicated by the size of the bubbles in Figure 3 above. Figure 10 expresses the results after weighing products by their share in world trade. For Egypt, packaged medicaments in the chemicals sector top all 97 products that meet all PSM conditions whilst taking trade into account. Accordingly, over a quarter of all active industrial policy efforts should be directed towards addressing market imperfections for that product. This is an abstract statement, but it indicates that this sector should have very high priority. This may mean that a quarter of the funds or budget directed to industrial policy efforts - from training and service development programmes to international fairs, etc., which deal at heart with market failures - should go to medicaments. With $\$ 337$ billion worth of world exports, packaged medicaments represent the seventh largest most-traded product in the world (over $2 \%$ of world exports). It is also quite complex (PCI $=2.43$ ), but luckily fairly close to Egypt's average distance; Egypt already occupies 33\% of the pharmaceutical community's products, as represented by the darkly shaded part of the bubble for pharmaceuticals (Figure 11a). The segments that Egypt currently occupies in pharmaceuticals are in the less-complex parts and have an RCA less than 1.

The second product group is seats (e.g. car and aeroplane seats), which is in the "other highly manufactured" sector; the third is inflated rubber tyres in the chemicals community (plastics and rubber). Despite being weakly complex $(\mathrm{PCI}=0.35)$, after controlling for exports, the fourth most important product group for Egypt is containers, bobbins and packages of plastics, which are also in the plastics and rubber section; the fifth is articles of iron and steel in the metals community (Table 5, for details see Tables A5 and A6). The proximity to oil and gas makes the chemicals industry an obvious candidate for Egypt. Input prices of the 
Table 4: Summary results by product groups.

\begin{tabular}{|c|c|c|c|c|}
\hline \multirow[t]{2}{*}{ Group } & \multicolumn{2}{|c|}{$\begin{array}{l}\text { Product Space } \\
\text { (Egy: 97; Tun: } \\
106 \text { products) }\end{array}$} & \multicolumn{2}{|c|}{$\begin{array}{l}\text { Strategic Bets } \\
\text { (Egy: 228; Tun: } \\
328 \text { products) }\end{array}$} \\
\hline & Egypt & Tunisia & Egypt & Tunisia \\
\hline Metals and manufactured articles made mostly of metal & 28 & 36 & $141 \uparrow$ & $181 \uparrow$ \\
\hline Agricultural products & 24 & 16 & $1 \downarrow$ & 7\ \\
\hline Non-consumable animal and plant products & 16 & 14 & $5 \downarrow$ & $13 \downarrow$ \\
\hline Chemical and related products & 15 & 18 & $62 \uparrow$ & $92 \uparrow$ \\
\hline Non-metallic mineral products & 6 & 6 & $11 \uparrow$ & $16 \uparrow$ \\
\hline Mineral products & 4 & 0 & 0 & 0 \\
\hline Textiles and apparel & 3 & 11 & $5 \uparrow$ & $13 \uparrow$ \\
\hline Other highly manufactured and special-purpose goods & 1 & 5 & $3 \uparrow$ & $6 \uparrow$ \\
\hline
\end{tabular}

Source: Author's calculation based on Atlas of Economic Complexity data (Center for International Development at Harvard Unversity, 2016).

industry are dominated by oil and gas, and thus have been subject to a high degree of volatility. Nevertheless, with the decline in oil prices reducing the oil price gap between countries, the industry may lose the big advantage of cheaper inputs relative to competing countries with earlier higher relative oil prices. The gradual elimination of the energy subsidy in Egypt may reinforce this trend.

For Tunisia, now that importance in trade has been given significant weight, it should direct $8 \%$ of its efforts towards furniture in the highly manufactured and special purpose goods sectors ( $0.5 \%$ of all world exports). The following three sectors are all in plastics and rubber in the chemicals community, with PCIs above 1, with the exception of the plastic containers, bobbins and packages, on account of their highly traded volumes ( $0.3 \%$ of world exports). Three machinery sectors follow, with a $4 \%$ weight (Figure 10). Table 5 presents the top five products across the three methodologies.

Note that most identified products show positive year-on-year growth rates during the last 5-year and 20-year periods, in the range of $2-6 \%$ and $7-11 \%$, respectively, for Egypt's products, and $2-5 \%$ and $5-7 \%$ for Tunisia's. The only exception is parts for radio, TV transmission and receiver equipment exports, which have witnessed negative average growth rates during the last 5 years.

\section{Discussion: Shortcomings of the Product Space Methodology}

This section predominantly deals with the limitations of the PSM: It presents them, defends some and suggests simple solutions where possible. 


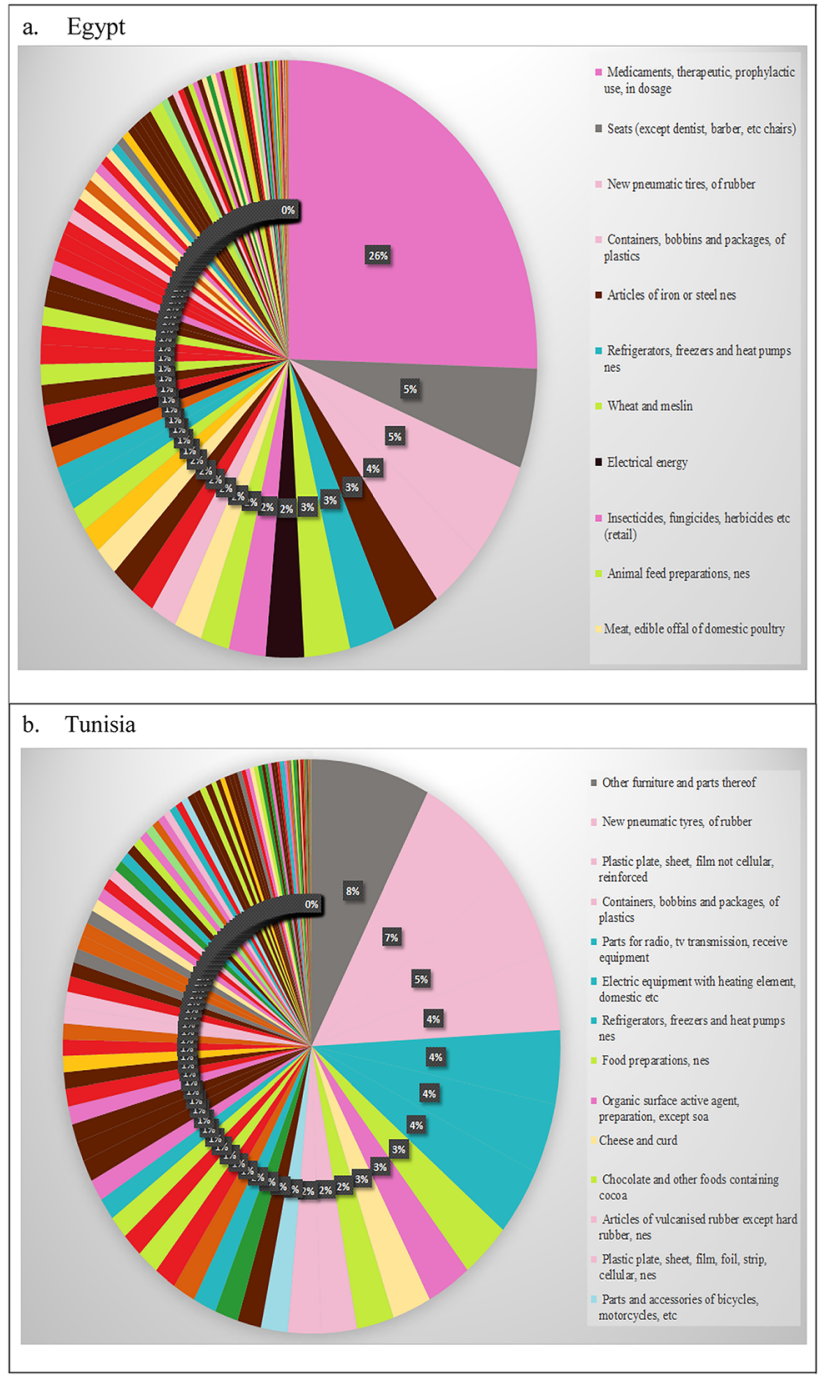

Figure 10: Upmarket products weighted by world trade, 2015.

Source: Author's calculation based on Atlas of Economic Complexity data (Center for International Development at Harvard University, 2016).

There have been some criticisms of the PSM (see Altenburg et al. 2016). The following section presents a number of essential shortcomings. First, although the PSM methodology instructs policy-makers where to go, it remains silent about how to get there (Altenburg et al. 2016). This is because it assumes that only inherent technical capabilities matter, in other words, supply conditions alone determine a 


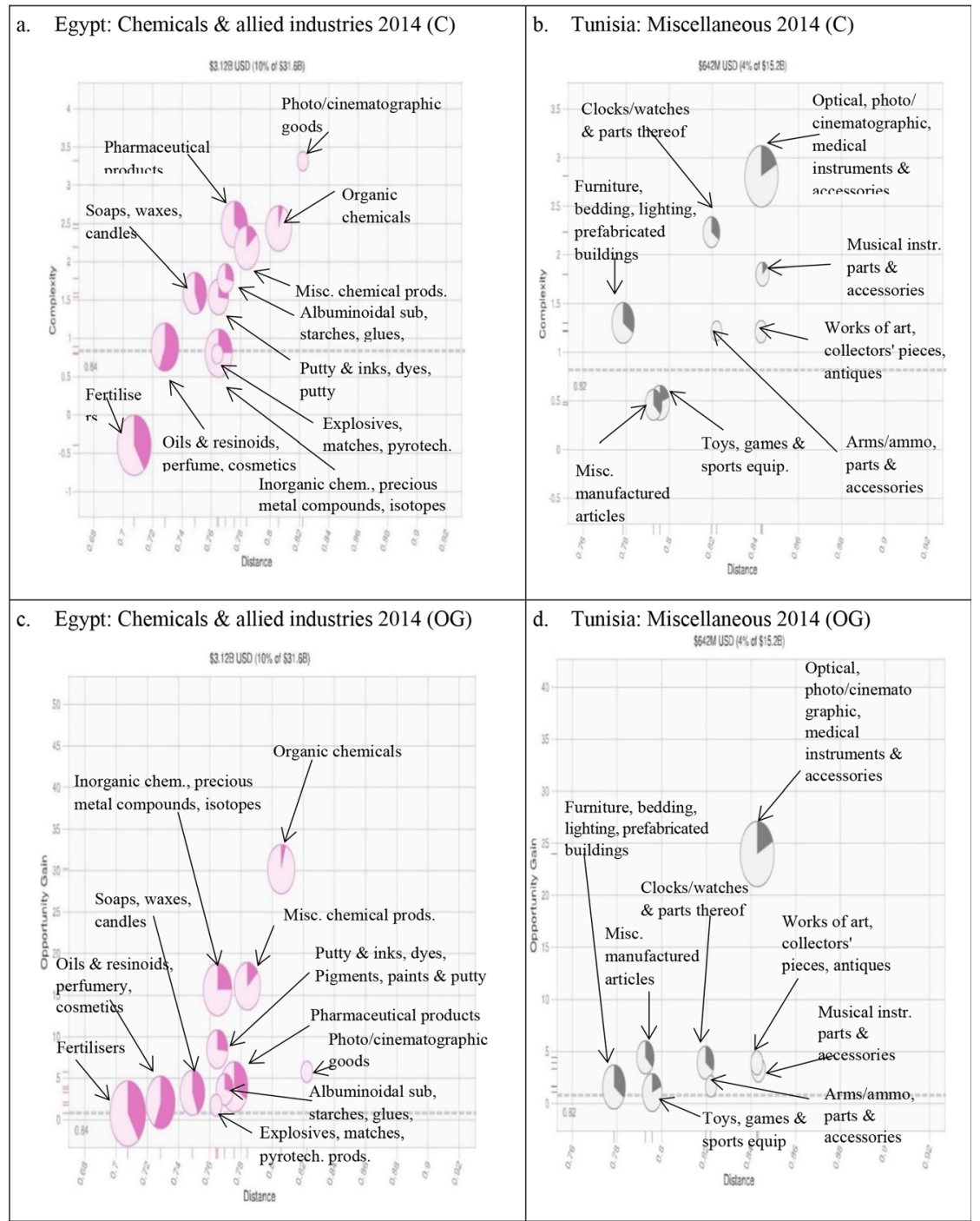

Figure 11: Product complexity and opportunity gain for top country export sectors. Source: Author, adapted from the Atlas of Economic Complexity (Center for International Development at Harvard University, 2016).

country's current and future exports, and countries will automatically head towards their future sectors. This excludes positive support from government to complement - or sometimes constrain - these favourable supply conditions. But government involvement indeed has implications on the results. For example, the decades-long 
Table 5: Top five upmarket export products by methodology.

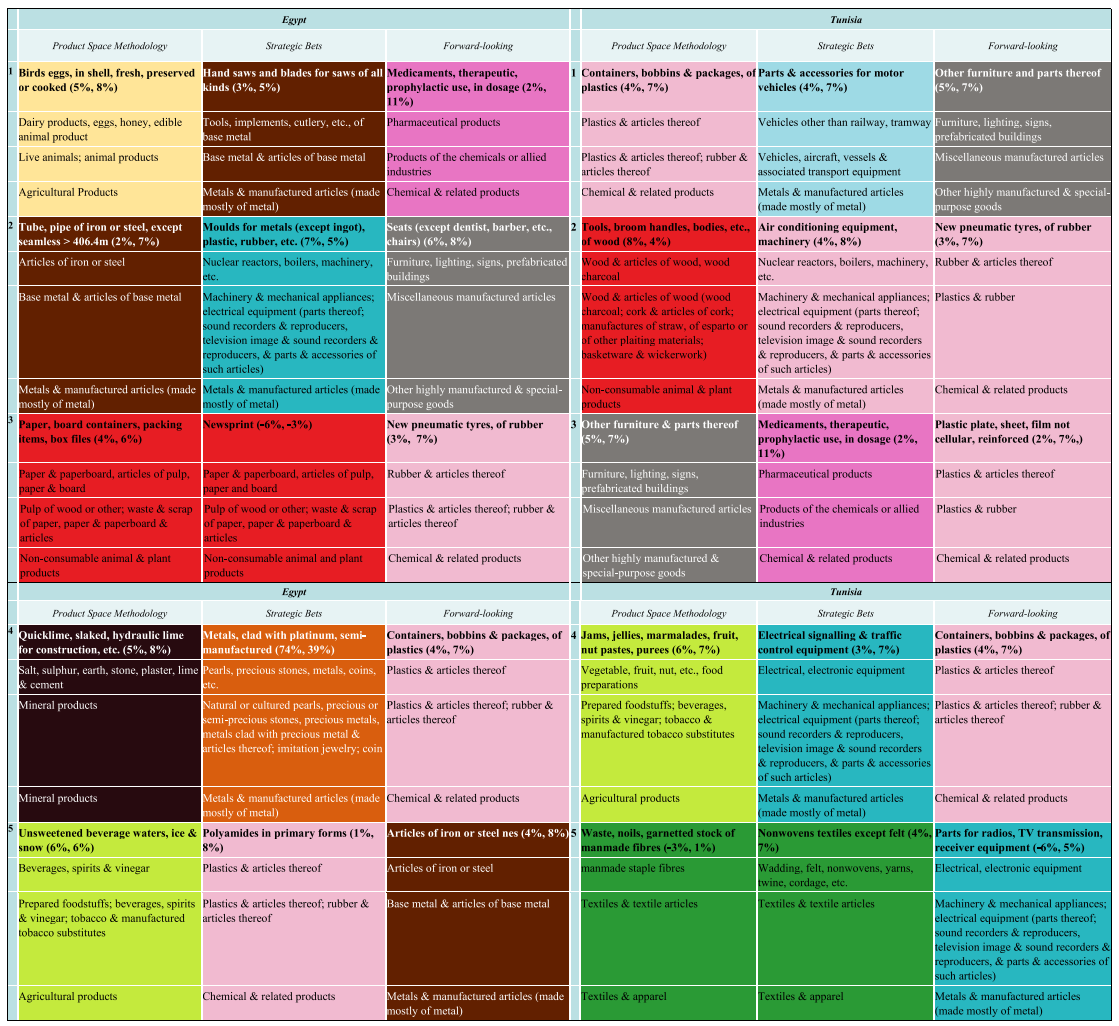

energy subsidy in both countries has had an effect on the current structure of the product space and, consequently, biases future results towards more energyintensive sectors (e.g. metals).

A typical extension of the approach is to explicitly request policy-makers' support for the proposed sectoral focus identified by the methodology, especially when market failures are present. The fewer market failures, the more pro-market - rather than pro-business - the policy should be in order to improve the business environment, namely by carrying out institutional reforms and reducing businessgovernment transaction costs without creating cronies (Diwan and Haidar 2016). In more recent papers industrial policy plays an integral role in achieving the sectoral jumps. In fact, Hausmann, Matovu et al. (2014) specify four major principles of a more interventionist industrial policy: 1) legitimacy: It should be shown that support is in the public interest, resulting in net benefits; as such, it should be directed at 
increasing productivity, not compensating for weak productivity; 2) focus on public inputs and spillovers: Support should provide public inputs to maximise spillovers, not provide private subsidies; 3) co-financing of the private sector to screen the viability of potential interventions (e.g. government could guarantee the first $\mathrm{x}$ years of rent for privately built industrial zones to remove some of the risks associated with the investment) and; 4) transparency and accountability: to limit rent-seeking, increase legitimacy and signal integrity (e.g. by setting ex ante success criteria publicly, weakly performing initiatives can be identified early and either corrected or terminated). Additionally, where government intervention is more crucial, what is needed is to put in place a robust, transparent and structured process of social dialogue and stakeholder consultation in policy design, implementation and learning - a dialogue that includes the government, civil society, industry and academics (Altenburg et al. 2016; Altenburg and Lütkenhorst 2015; El-Haddad 2016; Loewe 2013; Vidican et al. 2013).

Next, the PSM completely ignores the demand side. However, gaining access to a particular value chain is not straightforward and relies heavily on power asymmetries that also affect prospects for future upgrading (Fortunato, Razo, and Vrolijk 2015). Such obstacles originating from the structure of the value chain are disregarded in the product space analysis. If they are taken into account, then captive value chains should be avoided. Instead, sectors in modular chains that provide opportunities for both penetration and upgrading should be selected (see Altenburg et al. 2016; Altenburg 2006; Gereffi, Humphrey, and Sturgeon 2005; McCormick and Schmitz 2001; Schmitz and Knorringa 1999). Hence, the relevant question is how are value chains identified in this analysis (pharmaceuticals, plastics and rubber, furniture, seats and electric and electronic equipment)? Moreover, what does the global market structure look like? Are the industries competitive or oligopolistic? Are they prone to barriers to entry? For example, pharmaceuticals are divided into traditional and generic drug companies and are mostly supplier-driven global value chains, since they are a high-tech sector that relies heavily on technology and $\mathrm{R} \& \mathrm{D}$. This industry is the second largest industry worldwide, after tobacco, and is exposed to barriers to entry and collusion risks (Antonelli and Mariniello 2014). Indeed, the largest price-fixing and cartel scandals, such as that of Valeant drug company in 2015, and the 10-year scandal of the Swiss pharmaceutical company Hoffmann-La Roche, are vivid examples of how vicious and predatory this sector is. Thus, there should be detailed investigations of the identified sectors to provide further guidance on the chosen products and sectors.

The third shortcoming is the limited ability of trade classifications to reflect the actual production structure or to capture the skills embedded in exported products (Radosevic 2017, in Altenburg et al. 2016). A piece of exported garment, such as a 
high-end shirt, could be sewn in the country but designed, woven or spun, printed and dyed elsewhere. The ideal construction of the product space should use value added rather than final output. In defence of the PSM, these data are far less accurate and much harder to obtain than trade data, limiting the feasibility of this approach. Moreover, PSM identifies upmarket sectors by taking product sophistication into account, which implicitly reveals the skill level embedded in the final product.

The fourth weakness pertains to the static nature of the approach. PSM looks at just one point in time, one year, and bases its product selection on that. In principle, one can repeat the analysis every year, but this would still not introduce the required dynamism to the approach. Take Germany as an example. Because of its superior technological abilities among countries worldwide, it is likely to expand the space or the frontier in the future to include a larger number of more sophisticated products that did not exist in the product space of the previous years. The current version of the methodology is unable to predict these potential future changes. This is the reason why the methodology assigns Germany, counterintuitively, such a small opportunity value. A dynamic methodology will not produce that error. More generally, the approach is unable to anticipate future changes in framework conditions.

There are alternatives to dealing with the methodology's shortcomings. One would be to combine its results with other approaches, such as the technology foresight approach, which identifies upgrading sectors under more realistic assumptions of uncertainty about future economic and technological trends. The approach combines data analysis and quantitative prediction techniques with expert knowledge and foresight, major stakeholder input and societal dialogue (United Nations Industrial Development Organization 2005; Altenburg et al. 2016). Another alternative would be to weigh the PSM sectoral results using an index that incorporates additional aspects, including world trade (as in this paper), ecological sustainability, food security, expected shifts in technology and other factors policy-makers may be interested in or have raised concerns about. Though, of course, this would introduce complications to an approach for which simplicity is its main attraction.

\section{Conclusion}

Growth and employment come from export diversification and structural transformation towards the production of increasingly more sophisticated, highervalue products. These products create high-quality employment with higher wages. Egypt and Tunisia have achieved limited levels of diversification and structural transformation. They produce only slightly complex products. This structure is unable to move the two countries onto an inclusive, high-growth path buttressed by healthy growth of the private sector as the source of quality jobs. 
This paper has identified leading export sectors for Egypt and Tunisia based on the Product Space Methodology. The approach emphasises technical spillovers in production and exports, identifying unexploited opportunities for each country.

Using a variant of the PSM that takes into account global trade patterns and the trade-off between the quantity and quality of jobs created suggests that - in order to exploit its potential - Egypt should focus on medicaments in the pharmaceutical sector, which are part of the chemicals product community. Of course, statistically, the chemicals industry and pharmaceuticals are proximate, but there are huge variations within both of them in terms of R\&D intensity, for example. So the opportunity may be in pharmaceutical packaging or the formulation of pharmaceutical "commodities" or generics - not in developing new pharmaceuticals. The chemicals industry is an obvious candidate for Egypt, given Egypt's position in the product space and its proximity to oil and gas, the marked size and growth in the trade of chemicals, and the sector's connectedness in the space.

Egypt should also focus on products in the category "other highly manufactured goods", such as seats (car, aeroplane, swivel, etc.) and also on "other products" in plastics and rubber in the chemicals community, such as rubber tyres and plastic containers. The last of the top five products are iron and steel articles in the metals community.

Tunisia should emphasise furniture in the "highly manufactured and special purpose goods" sector and products in the chemicals industry. The latter are those products with greater complexity in comparison to the identified products in Egypt's chemicals sector. Given Tunisia's greater accumulated knowledge and its relatively advanced position in the space compared to Egypt, the country should also support some electronics sectors. Electronics constitute the second-largest community in world trade and are well-connected in the product space.

The next step for research is to look at value chains identified in the analysis: pharmaceuticals, plastics and rubber, furniture, seats, and electric and electronic equipment. What does the global market structure of these products look like? Are the industries competitive or oligopolistic? Are there substantial barriers to entry? The pharmaceutical industry, for example, ranked second globally in terms of barriers to entry and the risk of collusion. The largest price-fixing and cartel scandals are usually in this sector. More generally, all market failures pertaining to the target sectors should be detected. A detailed investigation of the identified sectors is required to further confirm the suitability of the sectors and determine the strength and nature of the required industrial policy.

Active industrial policies (IP) in these two countries have been marred by a history of cronyism and political capture (Black et al. 2020; El-Haddad 2008; 2015b; 2017; 2020). Nevertheless, IP remains indispensable on account of various market failures. As a result, to the extent possible, industrial policy should be pro-market 
rather than pro-business so that it improves the business environment without creating cronies. In implementing a more interventionist industrial policy, it is necessary to adhere to the four principles of good industrial policy-making of Hausmann, Matovu et al. (2014) and put in place a robust, transparent and structured process of social dialogue and stakeholder consultation in policy design, implementation and learning. This dialogue should include government, civil society, industry, trade unions and intellectuals. In that way, the new strategy will have broad ownership, which is a first step towards the inclusive growth these countries need achieve to ensure stability.

\section{Abbreviations}

$\begin{array}{ll}\text { COI } & \text { Complexity Outlook Index } \\ \text { ECI } & \text { Economic Complexity Index } \\ \text { EMP } & \text { Euro-Mediterranean Partnership } \\ \text { ERSAP } & \text { Economic Reform and Structural Adjustment Program } \\ \text { GDP } & \text { Gross domestic product } \\ \text { IP } & \text { Industrial policy } \\ \text { IS } & \text { Import substitution } \\ \text { ISI } & \text { Import substitution industrialisation } \\ \text { MENA } & \text { Middle East and North Africa } \\ \text { OG } & \text { Opportunity gain } \\ \text { OV } & \text { Opportunity value } \\ \text { PCI } & \text { Product Complexity Index } \\ \text { PSM } & \text { Product Space Methodology } \\ \text { RCA } & \text { Revealed comparative advantage } \\ \text { TCV } & \text { Thermostatically controlled valves } \\ \text { TFA } & \text { Technology foresight approach }\end{array}$

\section{Annex}

\section{A1 Contrasting Egypt and Tunisia}

This section serves to briefly introduce the two countries in terms of their past economic policies. It also informs on the countries' economic structures in terms of diversification, concentration, ubiquity and complexity. These variables elucidate the degree of structural transformation in each country - the latter is not only important for productivity growth but also for providing future opportunities. Where a country is today determines where it will be tomorrow, or a country's position in the product space today determines its position in it tomorrow. As a result, these variables assist in positioning each country into the World Product Space for Exports and then later assist in understanding the results we obtain. 


\section{A1.1 Main Landmarks of Egyptian and Tunisian Economic Policies}

Egypt and Tunisia share much of the same policies rooted in their common approach to economic development. The two countries were committed to publicsector-led, inward-looking, import-substitution industrial policies (ISI) during the 50s and much of the 60s. Since the mid-1960s, the two countries have experienced similar growth rates (an average of 2.94 and 2.74 for Tunisia and Egypt, respectively, through the 1995-2010 period, Figure 1), with Tunisia's gross domestic product (GDP) per capita remaining approximately 50\% higher than that of Egypt's (Figure A1). While ISI policies resulted in a significant degree of industrial development, it contributed very little to employment creation (Nabli 2007). Import substitution was effected through: 1) outright import bans, and 2) prohibitive import tariffs. For example, in Egypt an import ban on textiles and clothing was introduced in 1968. The ban was lifted in 1998 for textiles and in 2002 for clothing. Nevertheless, the ban was initially replaced by prohibitive tariffs. Only later-in 2000, 2004 and 2007-were substantial tariff reductions introduced (Presidential Decrees 429/2000, 300/2004 and 39/2007, El-Haddad 2012). Export promotion on the other hand included investment and financial incentives as well as the creation of private sector promotion agencies, which in Tunisia contributed to its exclusively export oriented offshore sector (cf. Rivlin 2009; Erdle 2011).

During the seventies both countries reversed that model towards a mixed economy model, officially termed an "open door policy”, or infitah. This model combined import substitution with export promotion policies, though with more of the latter in Tunisia.

Following the two oil price shocks - in 1973 and 1979 - coupled with the consumption phase that dominated the 1970s and much of the 1980, pressure mounted on foreign exchange resources, budgetary deficits widened (18\% in Egypt only 4.5\% in Tunisia; AfDB 2000; Azzam 2013) and debt largely accumulated. A severe negative trade balance placed further pressure on foreign exchange resources.

In response to the growing severity of the economic situation, Tunisia pursued an Economic Reform and Structural Adjustment Program (ERSAP) in 1986, as did Egypt a few years later in 1991. This period deepened the countries' integration into the international global market economy. Trade liberalisation was a cornerstone of the reform process and was marked by the two countries' accession to the World Trade Organization in 1995. Whereas Tunisia was among the first wave of Arab countries to join the Euro-Mediterranean Partnership and sign the Association Agreements in the same year, Egypt followed some years later in 2001. It is during this phase that the countries' absolute GDP per capita started to diverge more markedly, perhaps on account of Egypt's delayed market access to Europe 


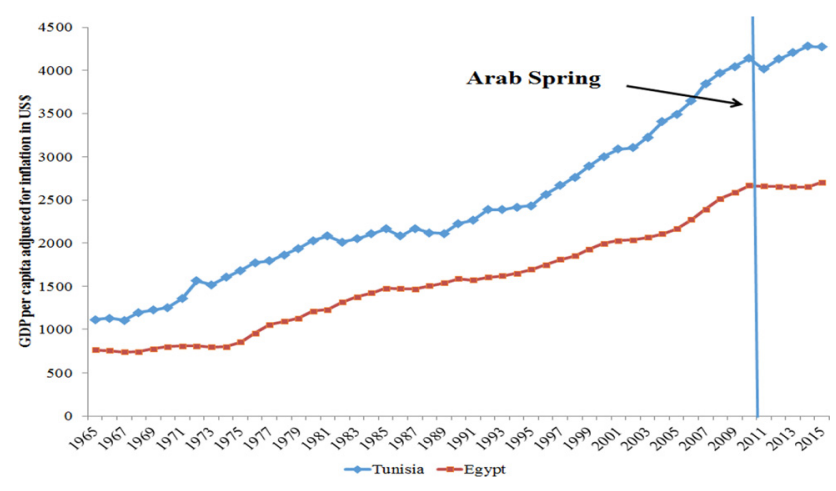

Figure A1: GDP per capita (1970-2015).

Source: Author, based on World Bank (2016).

(Figure A1). Indeed, Tunisia's average growth rate of 3.5\% was larger than Egypt's $2.7 \%$ in the years of asymmetric market access ${ }^{17}$ of the two countries (1995-2001).

The next stage, beginning in 2003, introduced more profound economic reforms that aimed to have lasting effects on any remaining import substitution strategies for both countries. The reforms included slashing customs and tariffs. As earlier mentioned the 2003-2007 period witnessed a remarkable growth of exports for both countries, which however could not be sustained on account of first the global financial crisis in 2008 and then the upheavals in 2011 (IMF 2009; Cinar and Gocer 2014; El-Haddad 2020).

\section{A1.2 Some Basic Differences Between Egypt and Tunisia}

Market Orientation. Egypt and Tunisia have made some progress, albeit varying, towards developing more private-sector-oriented economies. The private sector in Tunisia is nearly double that of Egypt in terms of private investment (in relative terms), which has increased from just under 16\% of GDP (15.92\% ) to about $21 \%$ between 1991 and 2010 in Tunisia and from just 7.6\% in Egypt to 10.5\% in the same period $^{18}$ (World Bank 2016). Similarly, the amount of credit offered to the private sector by Tunisia has been around double that of what Egypt has offered, both at the start of the ERSAP in 1991 and in 2010. Credit levels in Tunisia reached triple those of Egypt by 2015, with the percentage of credit to the private sector

17 Meaning that the two countries are allowed tariff-free access into the European Union, but the opposite is not true, which limits the competition from Europe.

18 Private investment covers gross outlays by the private sector (including private nonprofit agencies) on additions to its fixed domestic assets. 


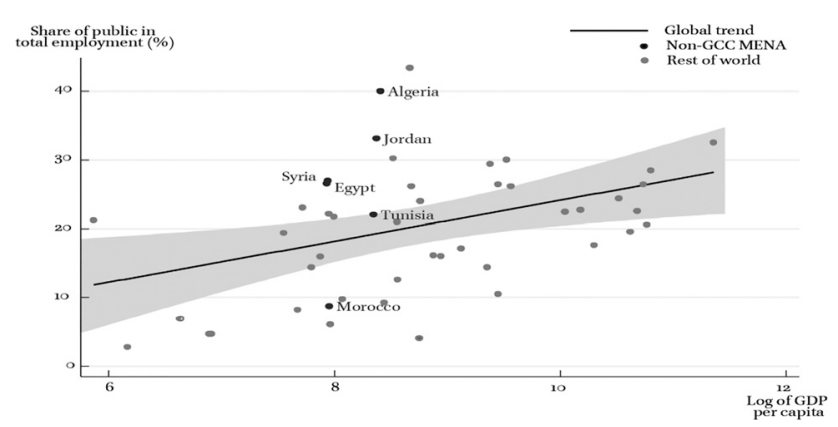

Figure A2: Public employment shares in international comparison.

Source: Author's based on data in Hertog, 2017.

Note: GCC countries are left out of this graph, as the large-scale presence of foreign workers in the private sector makes a direct comparison of private and public employment problematic. For Bahrain, more than half of citizens are employed by the governments.

being $80 \%$, compared to just 27\% in Egypt (World Bank 2016). Public-sector employment is nearly a quarter of the labour force in both countries (approximately 25 and $20 \%$ of the labour force; 7 and $6 \%$ public employment per capita in 2016 in Egypt and Tunisia, respectively), which is a significant proportion when compared to the rest of the world (Figure A2).

Trade Openness. Unlike Tunisia, Egypt is poorly integrated into the global economy. Trade openness (the ratio of non-oil exports and imports of goods and services to GDP), a measure of global integration, continued to deteriorate for Egypt, from 48\% in 1991 to just 30\% in 2015 (and 41\% in 2010). In Tunisia openness has grown steadily, from $78 \%$ in 1991 to $87.9 \%$ by 2014 , way above all countries in the Middle East and North Africa (MENA), which currently average 52\%. More generally, the gap between Tunisia's and Egypt's GDP per capita has widened over time. Just before the upheavals, by 2010 Tunisian GDP per capita had peaked much higher than Egypt's - to $\$ 4177$ (Figure 2). This is not merely a country-size effect but also reflects the varying industrial and economic policies of the two countries.

Export Diversification. Tunisia is also better diversified away from hydrocarbon exports. The share of hydrocarbons in total exports was just $8.9 \%$ in 2015 in Tunisia, compared to nearly triple that number for Egypt (25.7\%, WITS 2016), pointing to Egypt's greater reliance on resource-based sectors. Before the decline in oil prices, however, this share reached as high as 35\% in 2010 (only 15.9\% for Tunisia). This limited diversification is reflected in the Herfindahl-Hirschman product concentration index, which has steadily worsened for Egypt but improved for Tunisia. The 
Table A1: Herfindahl-Hirschman product concentration index (selected years).

\begin{tabular}{lccccc}
\hline & $\mathbf{2 0 1 0}$ & $\mathbf{2 0 1 2}$ & $\mathbf{2 0 1 3}$ & $\mathbf{2 0 1 4}$ & $\mathbf{2 0 1 5}$ \\
\hline Egypt & 0.046 & 0.071 & 0.067 & 0.068 & 0.069 \\
Tunisia & 0.026 & 0.025 & 0.025 & 0.021 & 0.020 \\
\hline
\end{tabular}

Source: WITS (2016) database, mirror data.

Note: Herfindahl-Hirschman product concentration index is a measure of the dispersion of trade value across an exporter's products. A county with a preponderance of trade value concentrated in a very few products will have an index value close to 1 . Thus, it is an indicator of the exporter's vulnerability to trade shocks. Measured over time, a fall in the index may be an indication of diversification in the exporter's trade profile. Range of values: 0 to 1 . A higher index indicates that exports are concentrated in fewer sectors, whereas a country with a completely diversified portfolio will have an index close to 0 .

gap has widened - with Egypt's score doubling before being 3.5 times that of Tunisia's by 2015 ( 0.046 for Egypt, compared to 0.026 for Tunisia in 2010; increasing for Egypt to 0.069 and declining for Tunisia to just under 0.02 by 2015, Table A1). Thus, Egypt is quite vulnerable to trade shocks from changes in hydrocarbon prices.

Egypt's oil endowment is not even large enough for the entire population to enjoy higher standards of living. In fact, Egypt's oil reserves per capita are only a fraction of the reserves of other countries that are less specialised in the oil sector, such as Singapore, Canada, the Netherlands, Australia and Belgium. Egypt's economy is heavily reliant on oil compared to other countries with similar oil exports per capita,
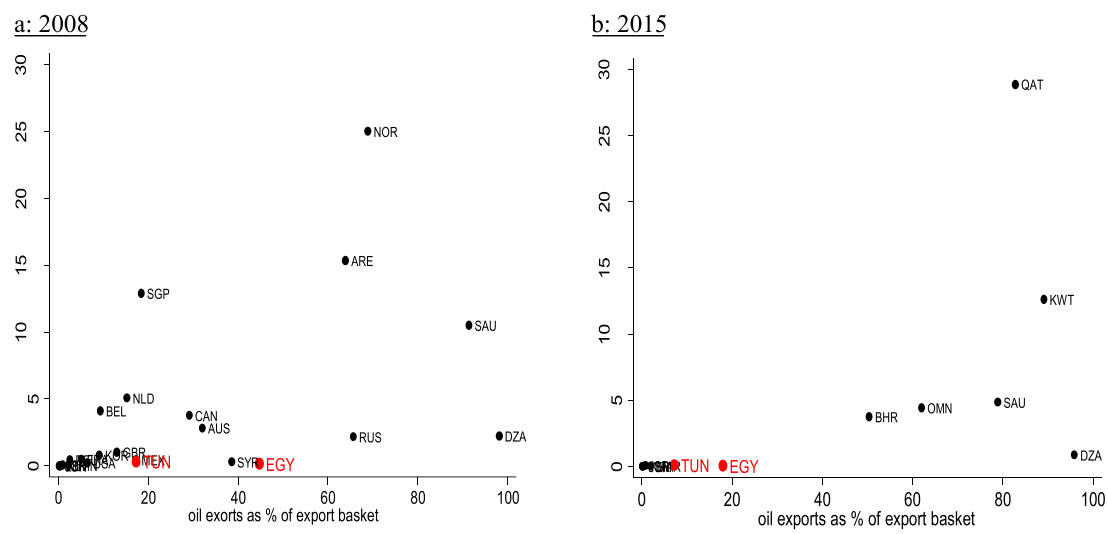

Figure A3: Per capita oil exports and oil exports as percentage of total exports in selected countries.

Note: Included MENA countries: United Arab Emirates, Algeria, Egypt, Israel, Jordan, Lebanon, Saudi Arabia, Syria and Tunisia.

Source: Author's calculations, based on World Bank (2016) and WITS (2016) database.

Note: Included MENA countries: Bahrain, Algeria, Egypt, Israel, Jordan, Kuwait, Morocco, Oman, Qatar, Saudi Arabia, Tunisia and Yemen.

Source: Author's calculations, based on World Bank (2016) and WITS (2016) database. 


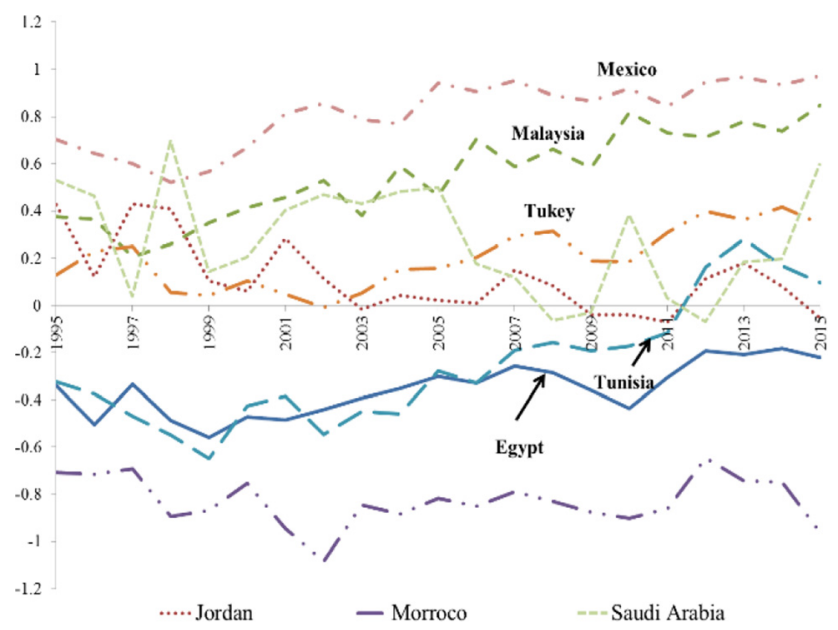

Figure A4: Economic Complexity Index, 1995-2015. Source: Author, based on Atlas of Economic Complexity data (Center for International Development at Harvard University, 2016). See Annex A2 for derivation.

such as China, India and the United States (Figure A3a). With the exception of Algeria (DZA), all other selected MENA countries with similar hydrocarbon endowment levels have lower concentrations in hydrocarbons compared to Egypt. Egypt's concentration is even greater than Syria's. Tunisia is also doing poorly in comparison to industrialised countries with similar - or even greater - endowment levels, but even in comparison to other MENA countries such as Israel, Jordan and Lebanon, which lay to the left of both countries. However, Tunisia is certainly doing a lot better than Egypt.

The situation has changed since the decline in oil prices starting in 2013, since when oil exports as a percentage of the export basket for the two countries nearly halved (Figure A3b). However, there remain plenty of countries with similar endowment levels but less concentration.

Hausmann et al. 2005, have introduced an index to measure export complexity, which is called the Economic Complexity Index (ECI). It combines information about a country's level of diversification and the ubiquity of the products it produces (Figure A4). Countries that are fairly diversified and export large numbers of products make products that are produced by few other countries, that is, they produce products that are less ubiquitous or common (Figure A5). Compared to all other countries, Egypt and Tunisia are average in their levels of diversification and produce products that are in the middle of the ubiquity distribution range. In comparison, China is the most diverse country in the world and, at the same time, the least ubiquitous, producing all sorts of non-common products that one can think of. Being located on top of the regression line means that, for their level of 


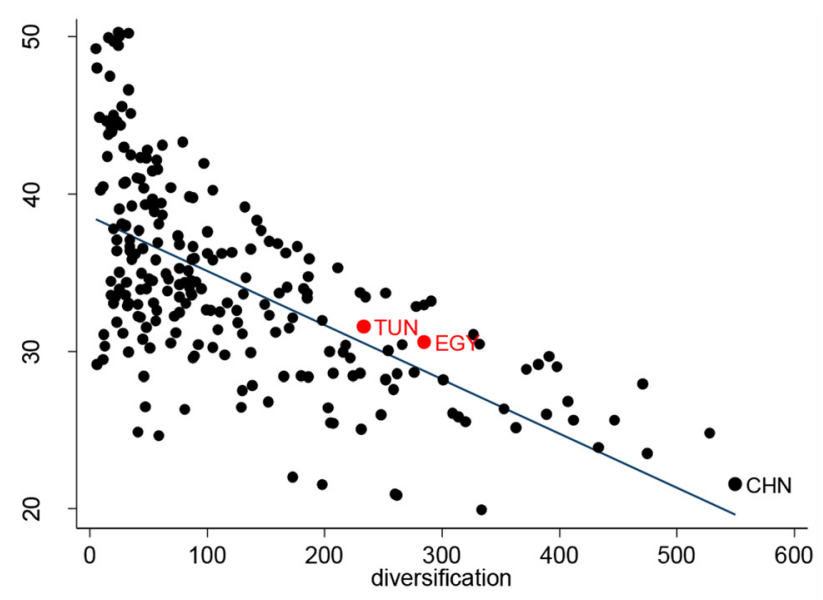

Figure A5: Diversification and ubiquity (2015).

Source: Author, based on Atlas of Economic Complexity data (Center for International Development at Harvard University, 2016).

diversification, the countries could do better in terms of ubiquity, and vice versa. Overall, the two countries' ECI levels do not compare favourably to those of other oil exporters, such as Saudi Arabia, Mexico and Malaysia, which have upgraded their non-oil exports. Since 2006 Tunisia has maintained greater ECI levels compared to Egypt, though both have had mostly negative ECI levels, with Tunisia's only turning positive after 2011. Using UN COMTRADE data for 2015, Egypt ranked as the 137th (Tunisia 109th) most complex out of 234 countries in the world - a bit worse than the middle of the distribution - with Tunisia ranking a bit better. Within MENA, Egypt ranked ninth (Tunisia seventh) out of MENA's 19 countries. Despite being the better performer of the two more recently, there is still room for improvement by Tunisia.

\section{Annex A2 Terminology Definitions and Derivations}

\section{Opportunity Value (OV)}

To quantify the OV or Complexity Outlook Index (COI) of a country's unexploited prospects, we sum the "closeness", that is, 1 minus the distance, to the products that the country is not currently producing, weighted by the level of complexity of these products. We can write this mathematically as: 


$$
\mathrm{COI}_{c}=\sum_{p^{\prime}}\left(1-d_{c p}\right)\left(1-M_{c p^{\prime}}\right) \mathrm{PCI}_{p^{\prime}}
$$

PCI is the product complexity index of product $p^{\prime}$, Mcp is a matrix, that is, 1 , if country c produces product $\mathrm{p}$ and 0 (see elaborate definition in the derivation below in A2). Thus, the term 1- $M_{c p^{\prime}}$ ensures that we count only the products that the country is not currently producing. A Higher Complexity Outlook implies being in the neighbourhood of more products and/or products that are more complex (Hausmann, Hidalgo et al. 2014). The index measures the position of a country in the product space. A country with a higher COI is closer to more complex products that it is not currently making than a country with a lower COI. A country with a higher COI should have an easier time solving the "chicken and egg" problem associated with coordinating the development of new industries and the accumulation of their required capabilities. Industries that are closer to a country's current capabilities should have fewer coordination failures to resolve and, hence, provide an easier path to the accumulation of capabilities (Hausmann, Hidalgo et al. 2014).

\section{Economic Complexity Index (ECI)}

$\mathrm{ECI}$ is a scale that uses the theory of - and calculations for - economic complexity to rank countries according to their levels of complexity. Hausmann, Hidalgo et al. (2014) have shown that when a country produces complex goods in addition to a high number of products, it is typically more economically developed or can be expected to experience fast economic growth in the near future. Consequently, ECI levels can be used as a measure of economic development. To determine the ECI level, they take a country's diversity level (how many different products it can produce) and divide by the ubiquity of those products (the number of countries able to make those products). To generate a more accurate measure of economic complexity, they correct the information that diversity and ubiquity levels carry by using each to correct the other. For countries, this requires the calculation of the average ubiquity level of the products that it exports, the average diversity level of the countries that make those products, and so forth.

$$
k_{c, n}=\frac{1}{k_{c, 0}} \sum_{p} M_{c p} . \quad k_{p, n-1}
$$

For products, this requires the calculation of the average diversity level of the 


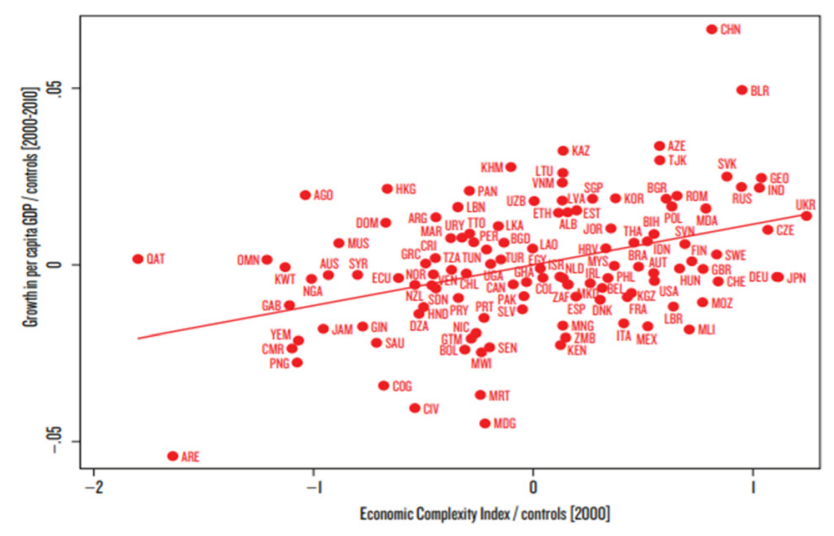

Figure A6: Complexity and GDP growth in international comparison.

Source: Hausmann, Ricardo, César A. Hidalgo, Sebastián Bustos, Michele Coscia, Alexander Simoes, and Muhammed A. Yildirim., The Atlas of Economic Complexity (2014, Figure 3.3, p. 29). By permission of The MIT Press.

countries that make them, and the average ubiquity level of the other products that these countries make.

$$
k_{p, n}=\frac{1}{k_{p, 0}} \sum_{c} M_{c p} . \quad k_{c, n-1}
$$

By inserting (2) into (1)

$$
k_{c, n}=\frac{1}{k_{c, 0}} \sum_{p} M_{c p} \frac{1}{k_{p, 0}} \sum_{c^{\prime}} M_{c^{\prime} p} k_{c^{\prime}, n-2}=\sum_{c^{\prime}} k_{c^{\prime}, n-2} \sum_{p} \frac{M_{c^{\prime} p} M_{c p}}{k_{c, 0} k_{p, 0}}=\sum_{c^{\prime}} k_{c^{\prime}, n-2} \tilde{\mathrm{M}}_{c c^{\prime}}
$$

Where: $\tilde{\mathrm{M}}_{\mathrm{cc}}, \equiv \sum_{p} \frac{M_{c^{\prime} p} M_{c p}}{k_{c, 0} k_{p, 0}}(3)$ is satisfied when $k_{c, n}=k_{c, n-2}=1$. This corresponds to the eigenvector of $\tilde{M}_{c, c^{\prime}}^{C}$ which is associated with the largest eigenvalue.

Since this eigenvector is a vector of ones, it is not informative. We look, instead, for the eigenvector associated with the second-largest eigenvalue. This is the eigenvector that captures the largest amount of variance in the system and is our measure of economic complexity. Hence, the Economic Complexity Index is defined as:

$E C I=\frac{\overrightarrow{\mathrm{k}}-<\overrightarrow{\mathrm{k}}>}{\operatorname{stdev}(\overrightarrow{\mathrm{k}})}$ Where $<>$ represents an average, stdev is the standard deviation and $\overrightarrow{\mathrm{K}}$ is the eigenvector of $\tilde{\mathrm{M}}_{\mathrm{cc}}$, associated with the largest eigenvalue (Hausmann, Hidalgo et al., 2014). 


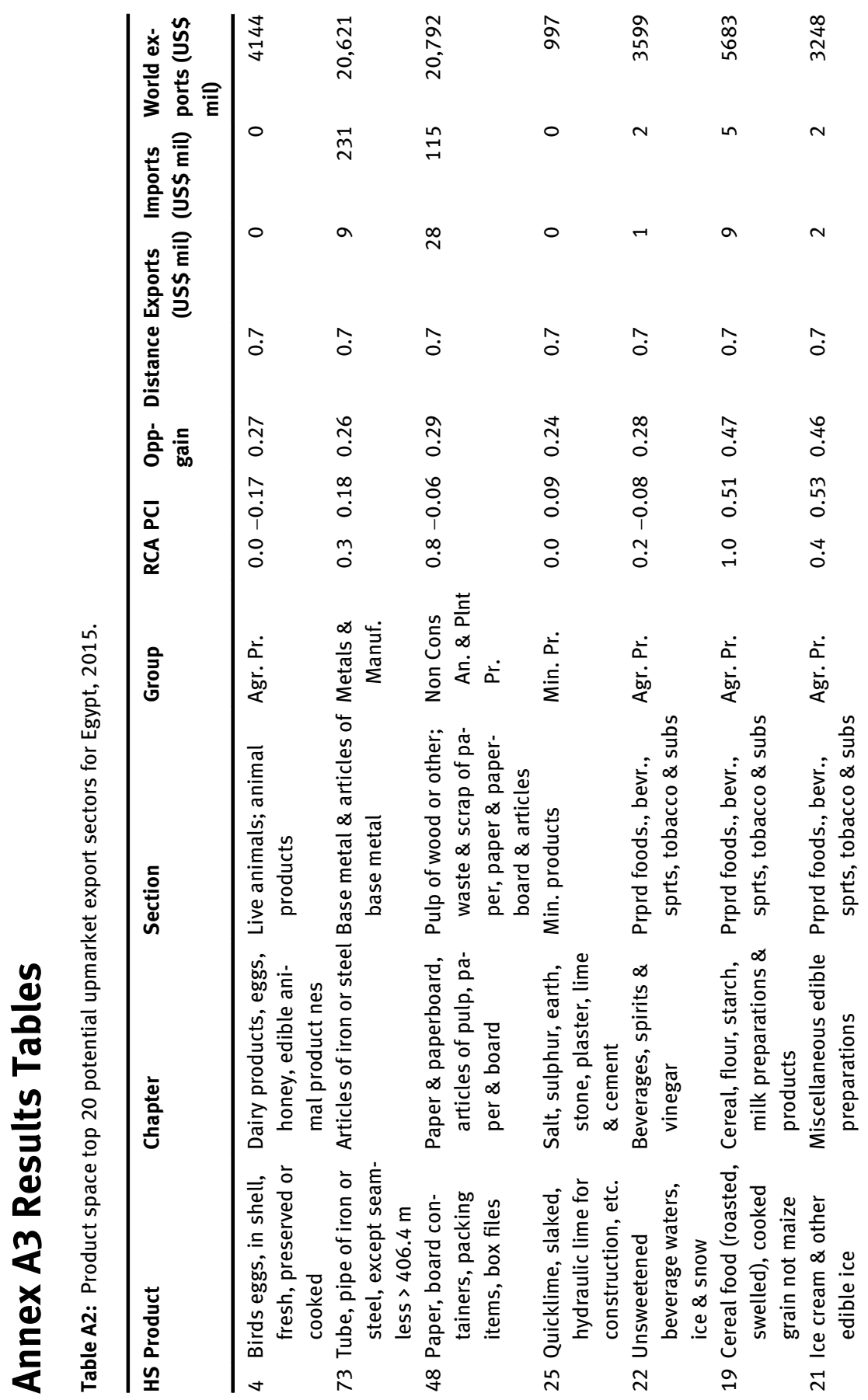




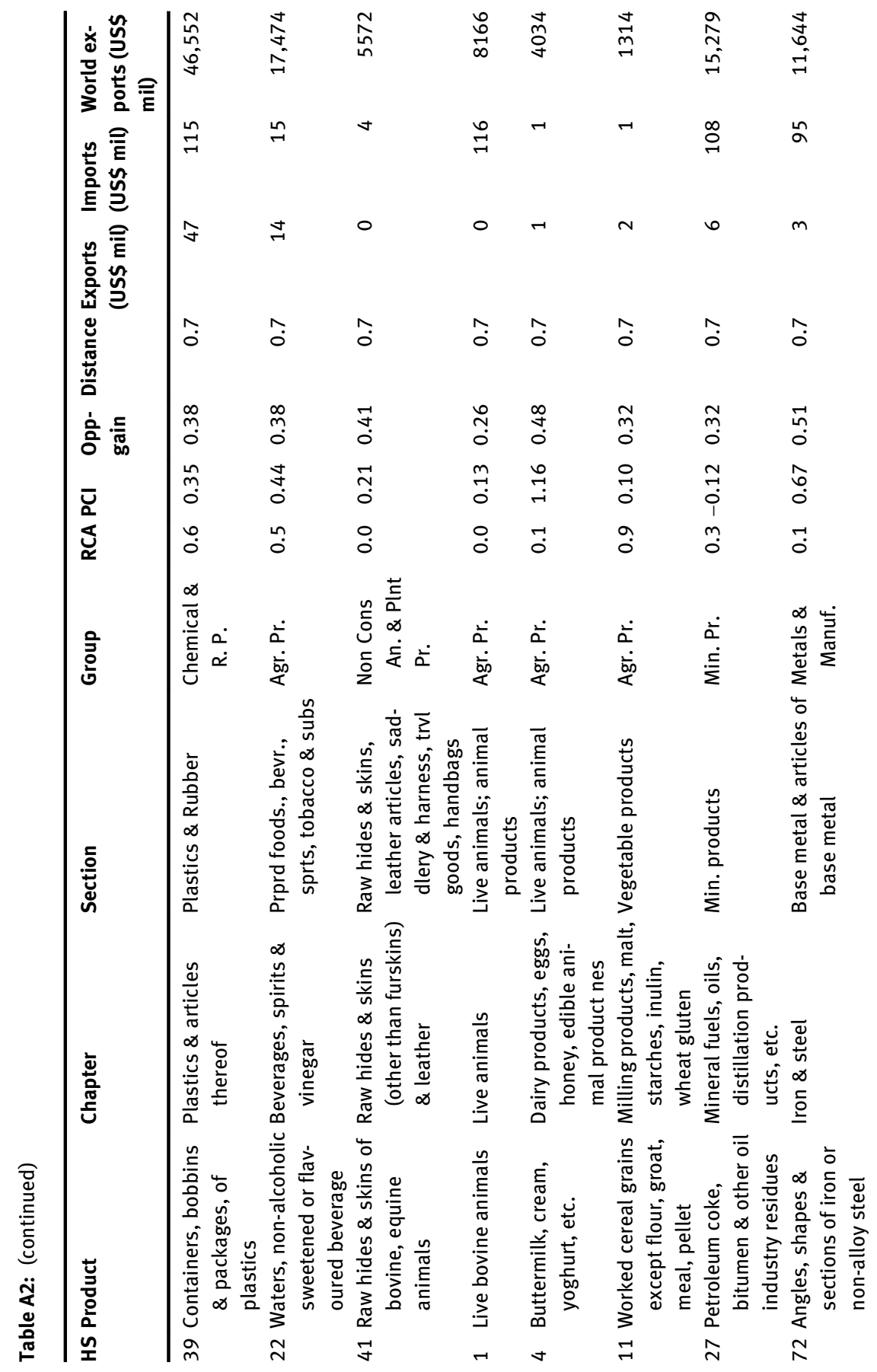




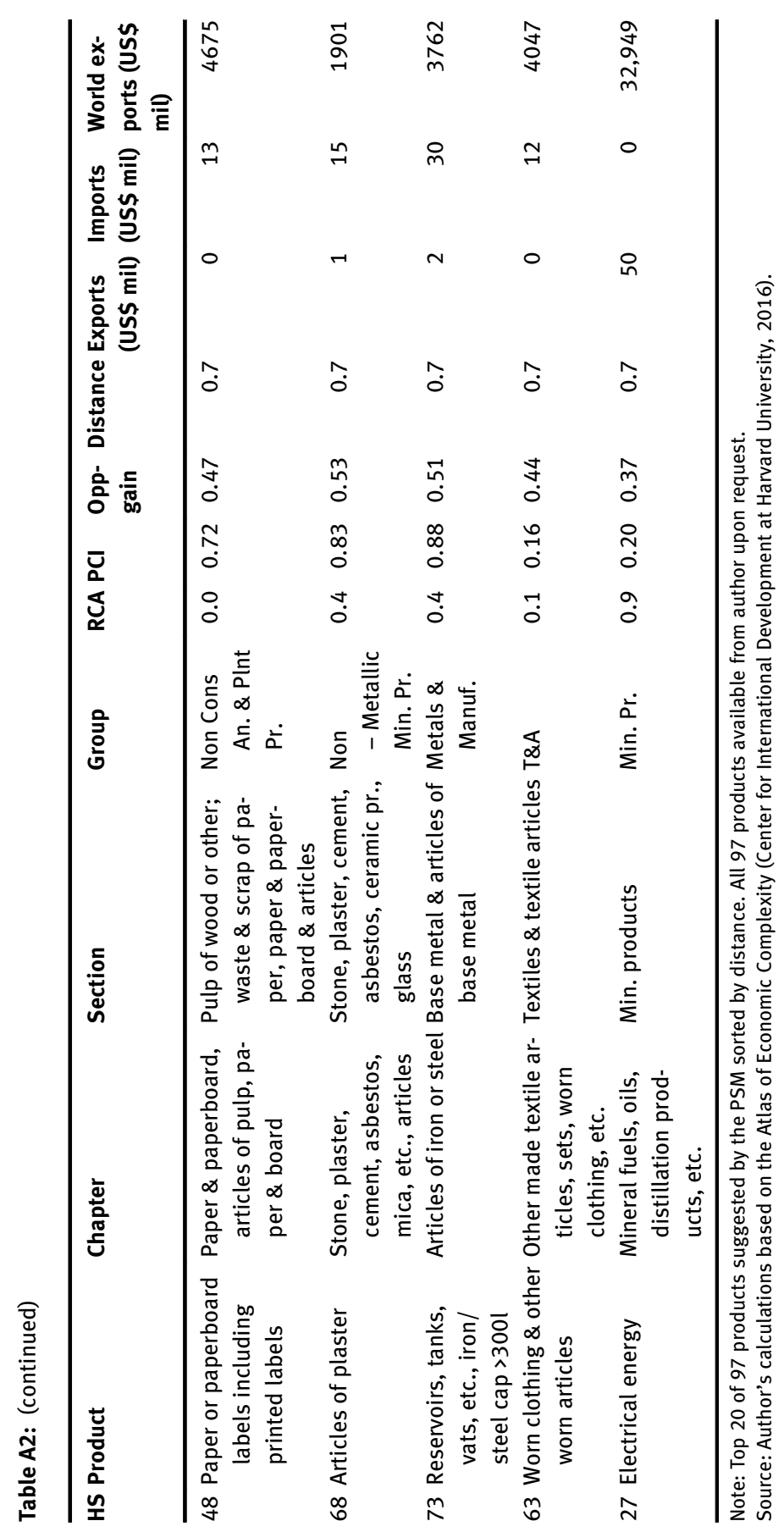




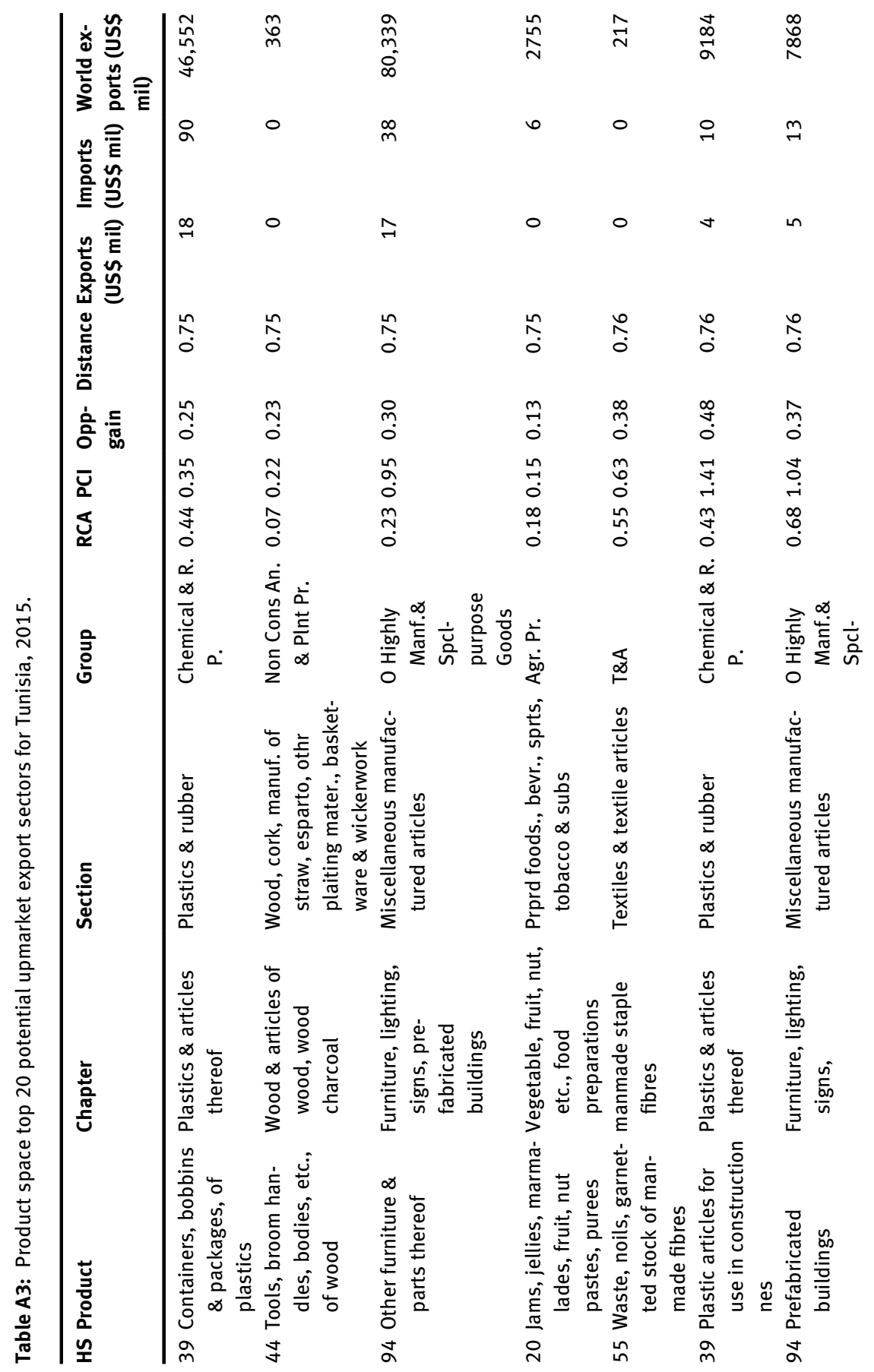




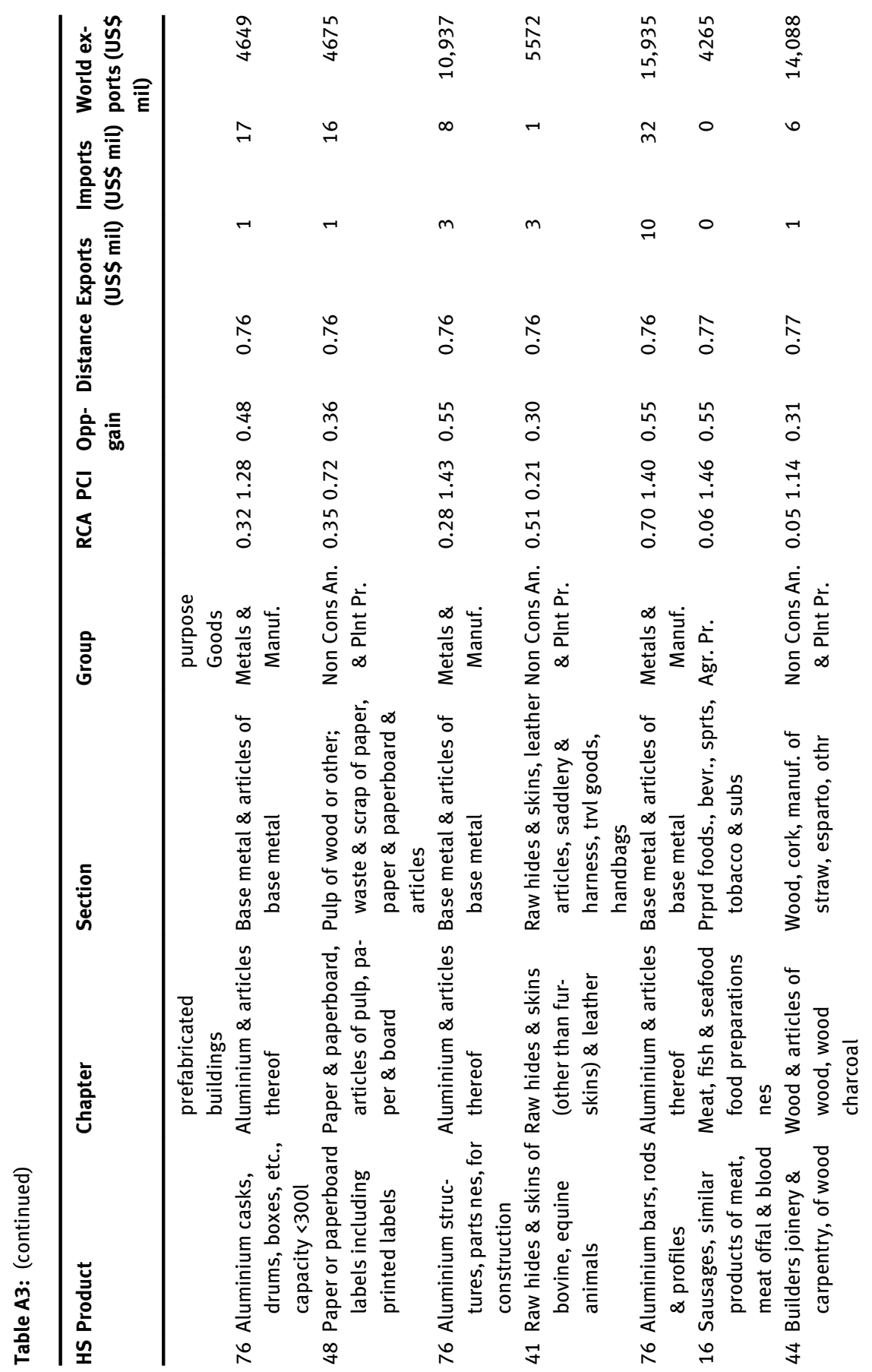




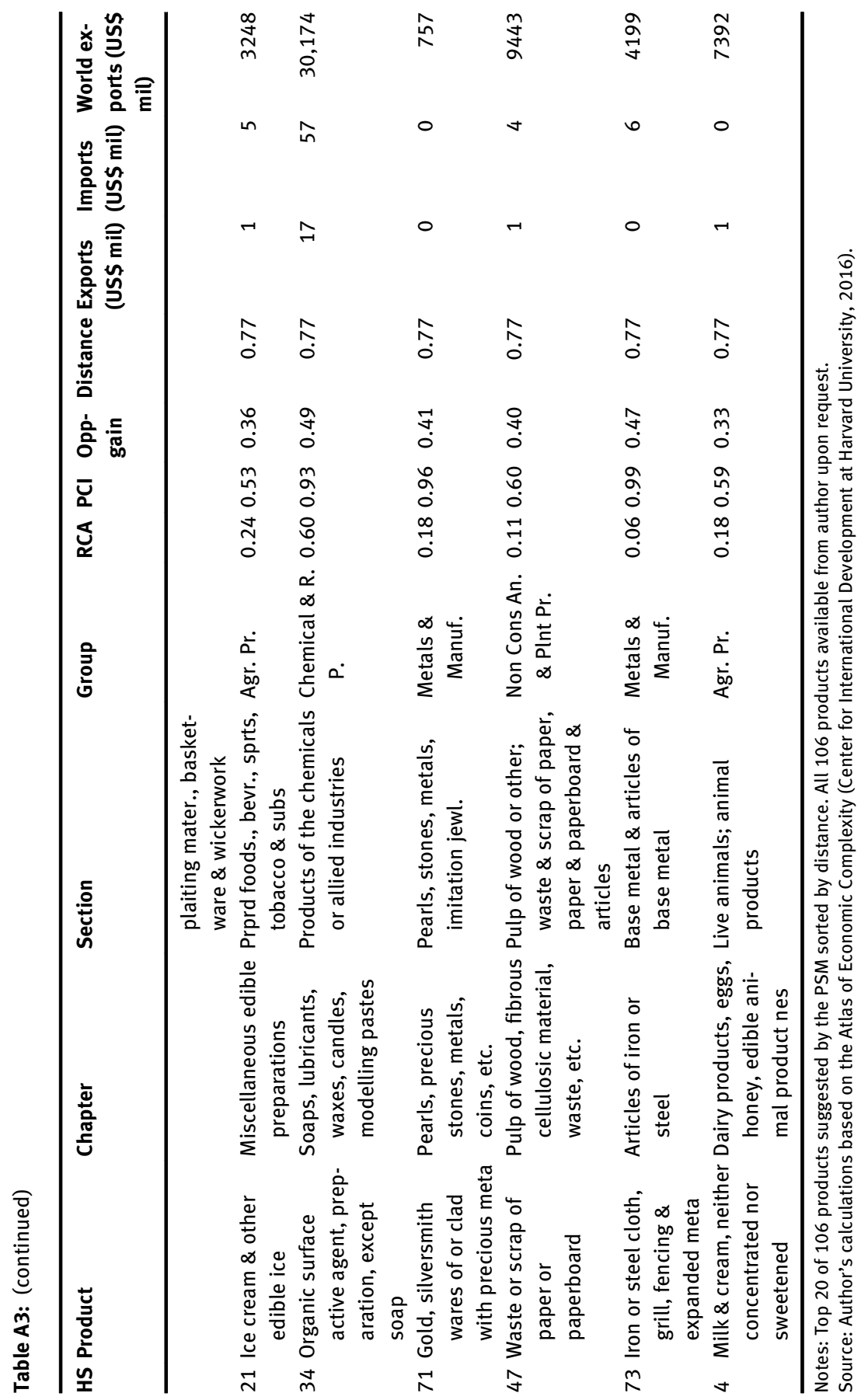




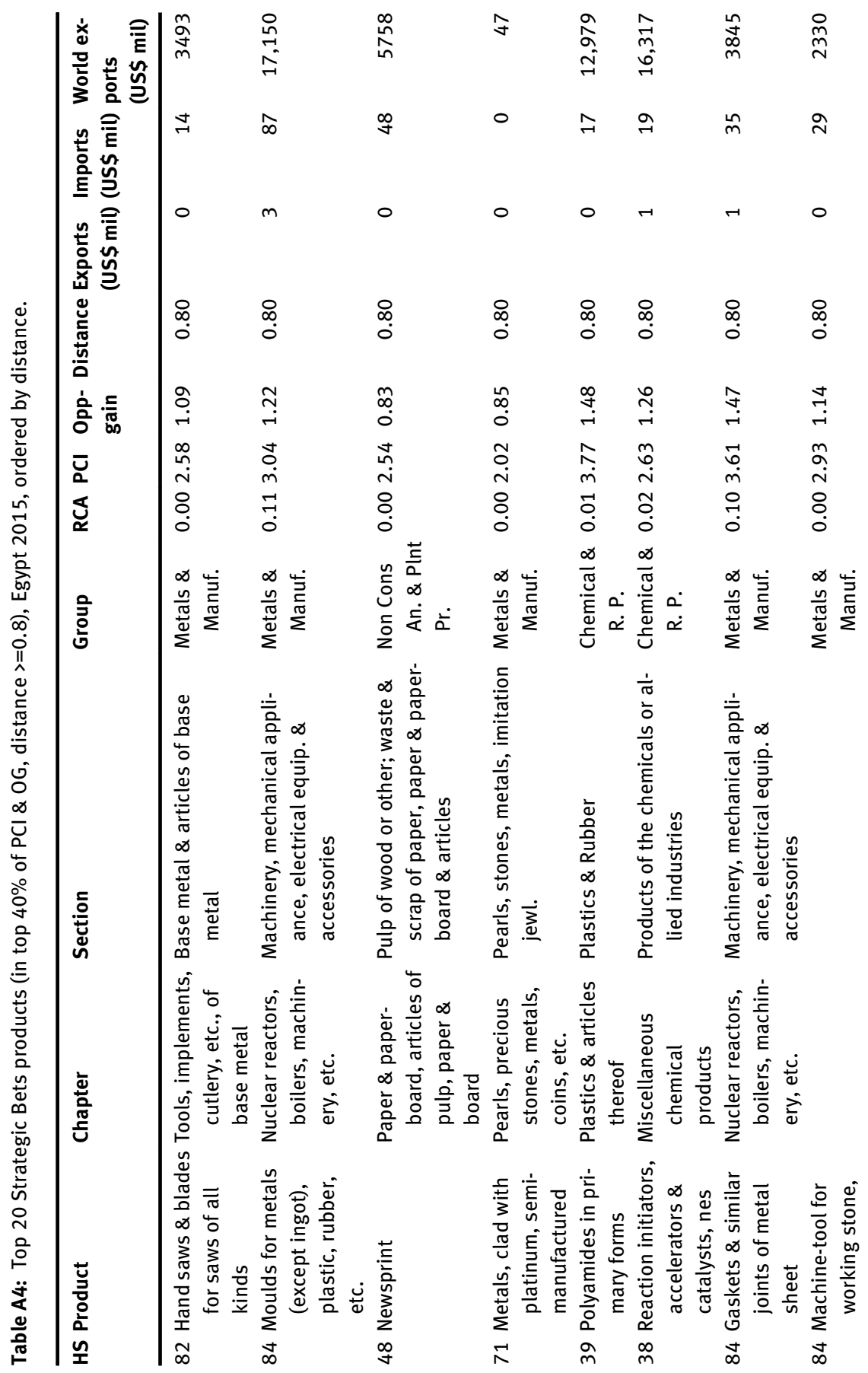




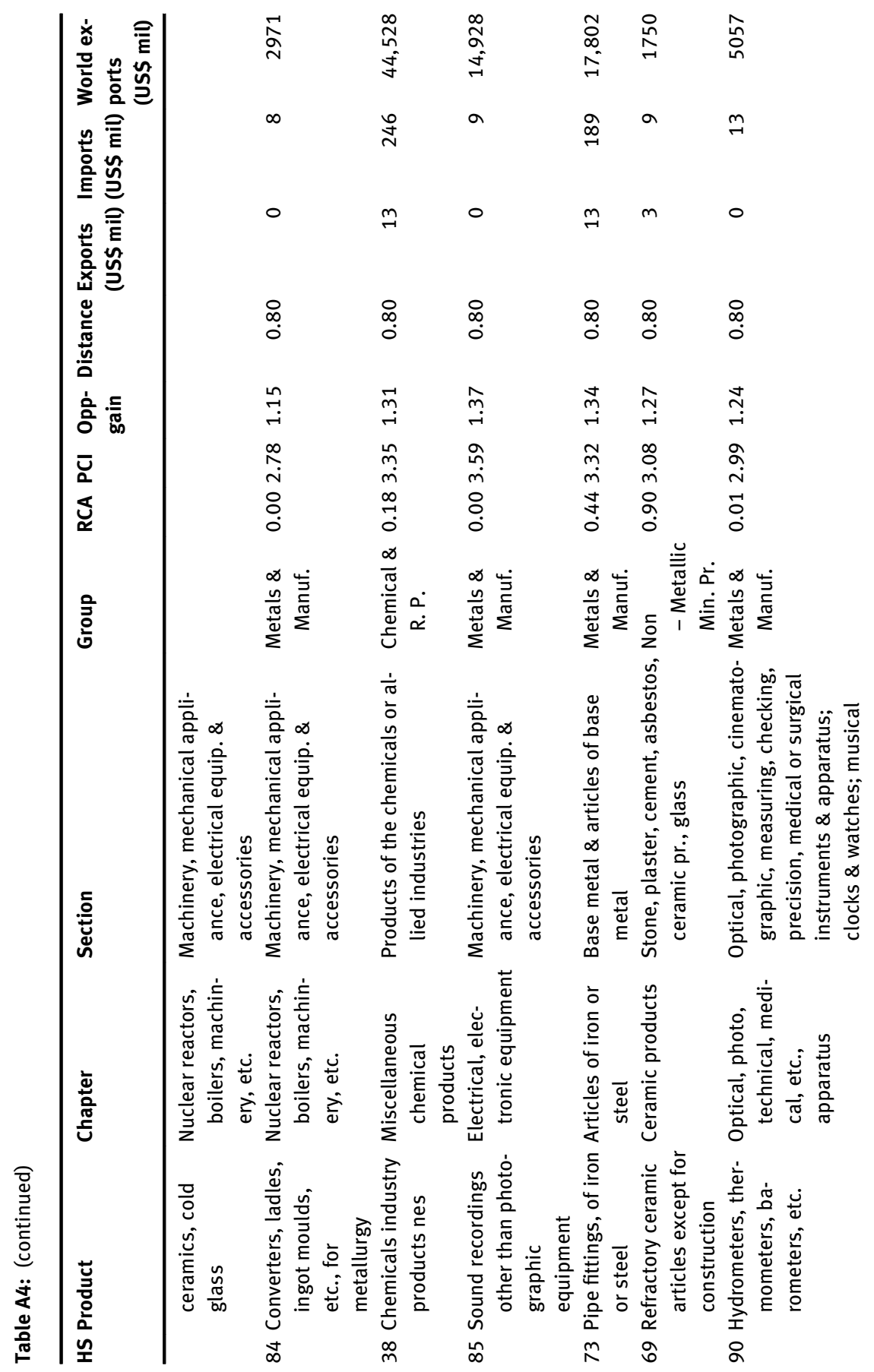




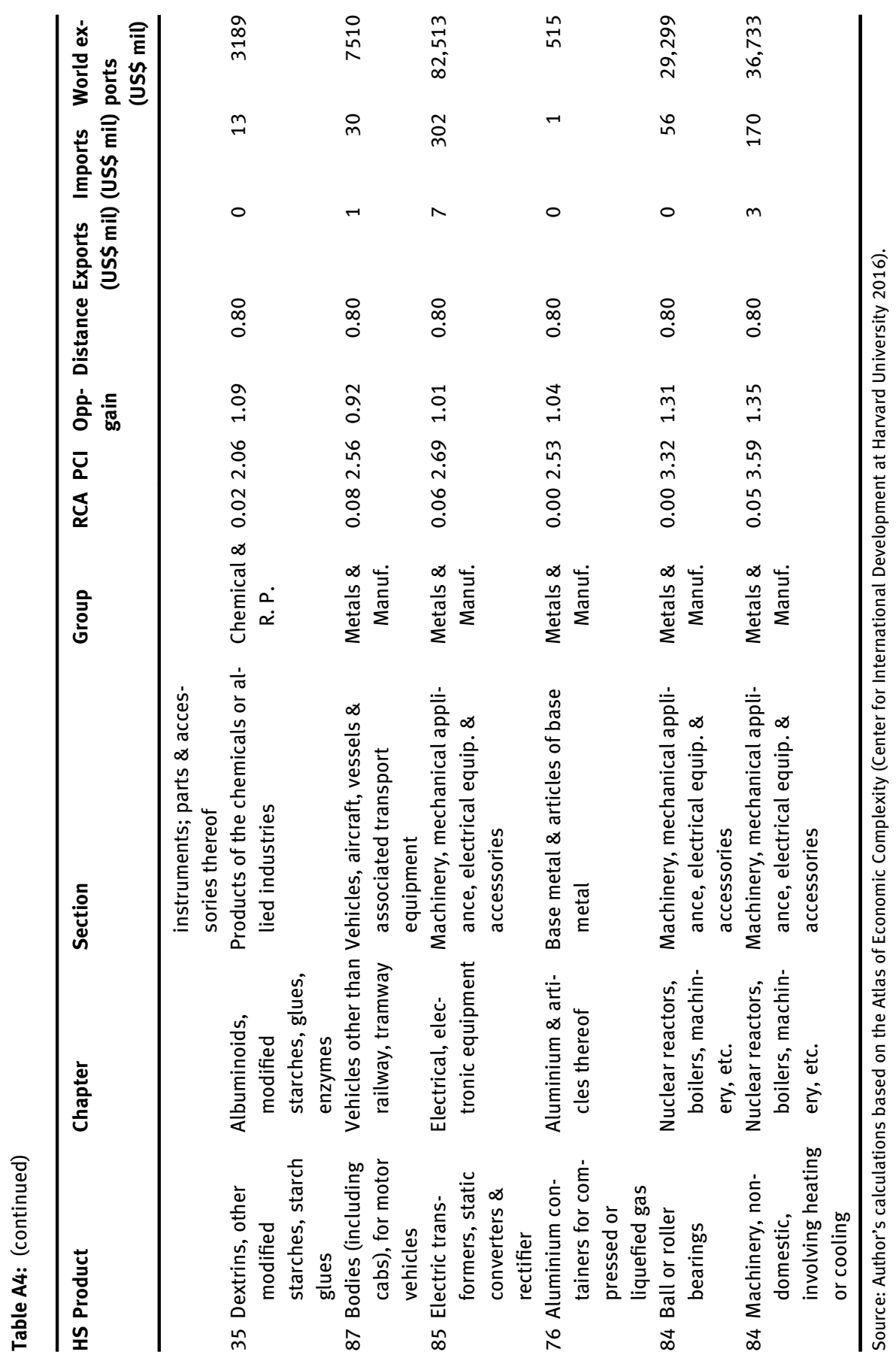




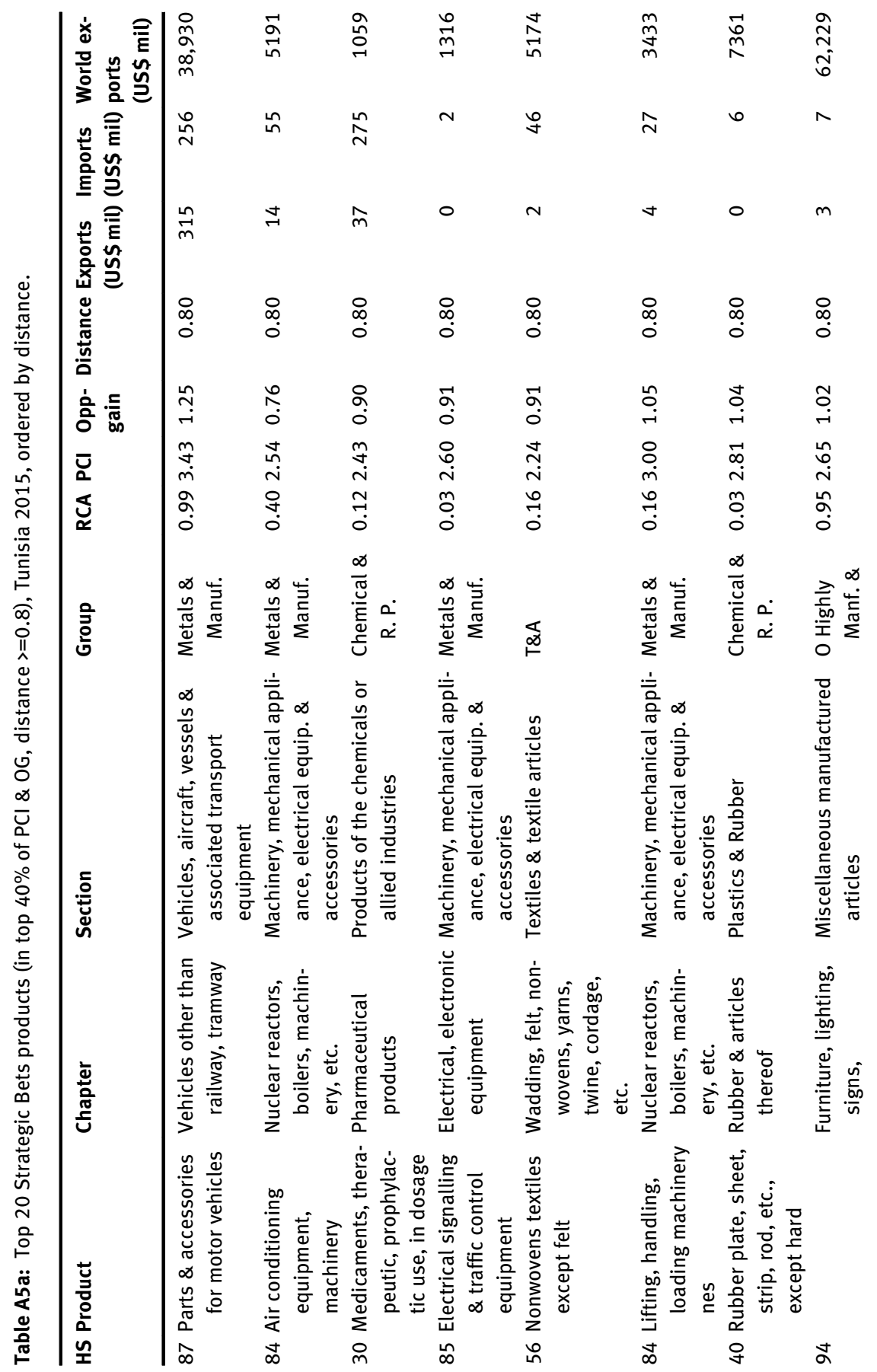




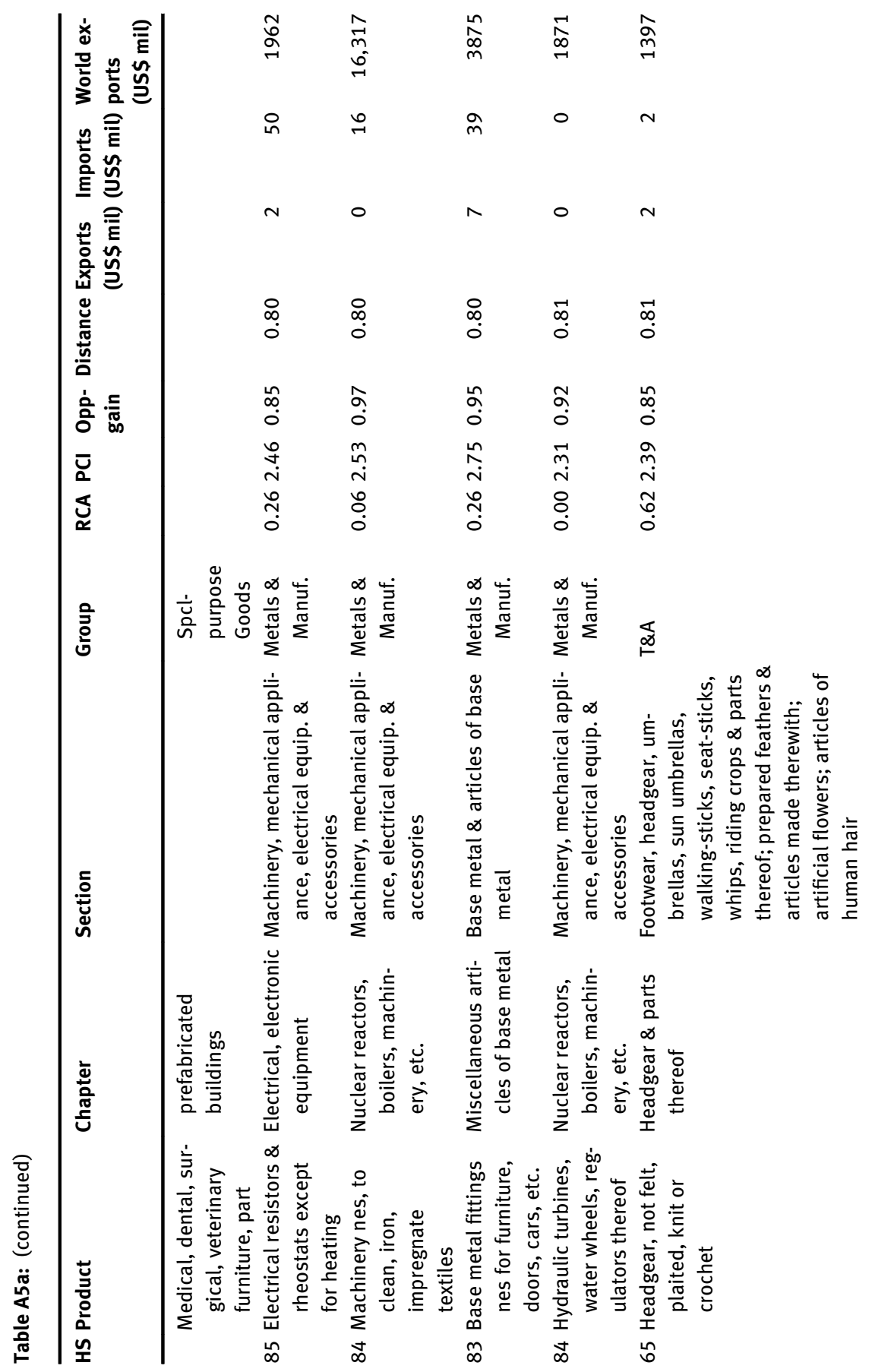




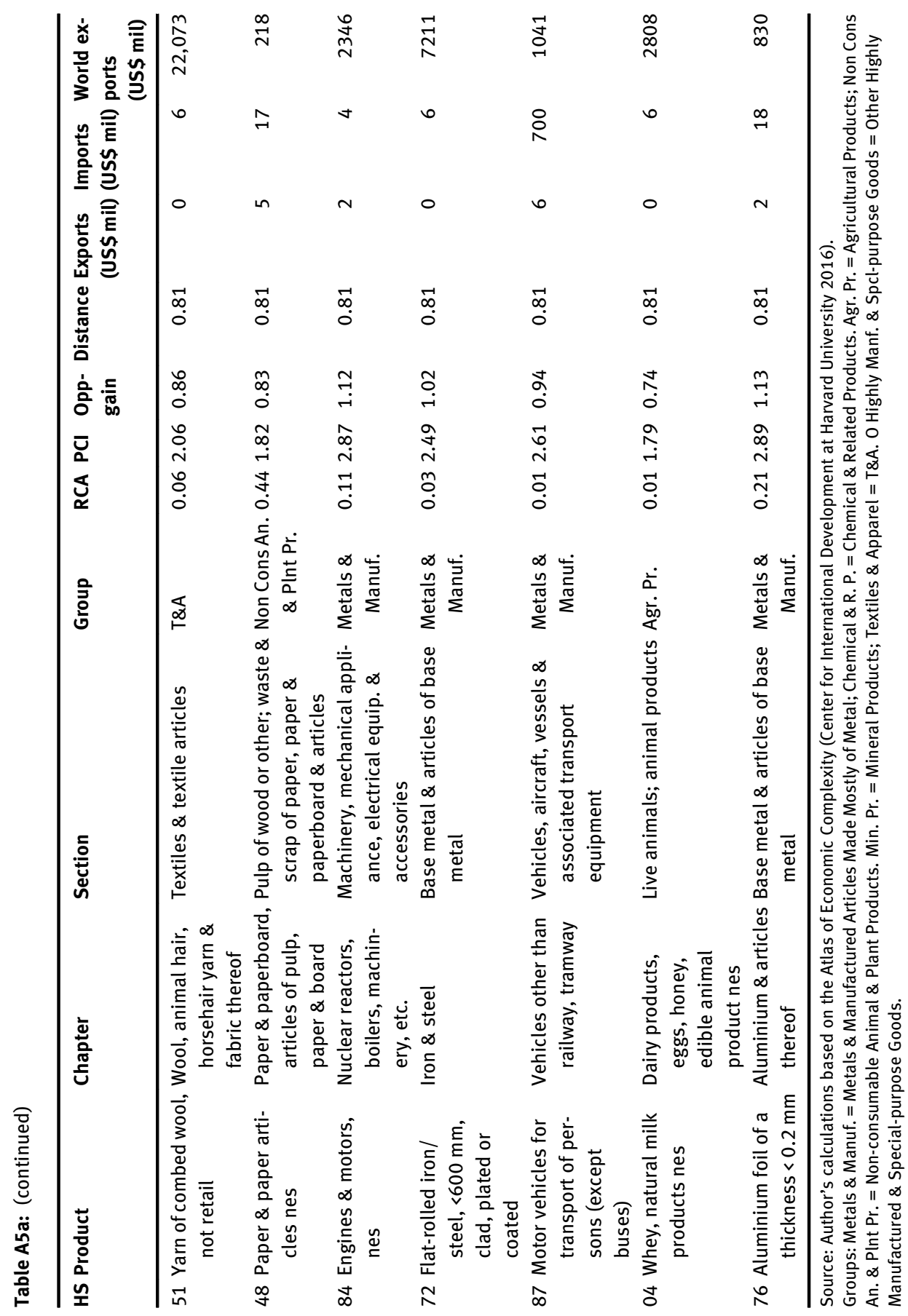




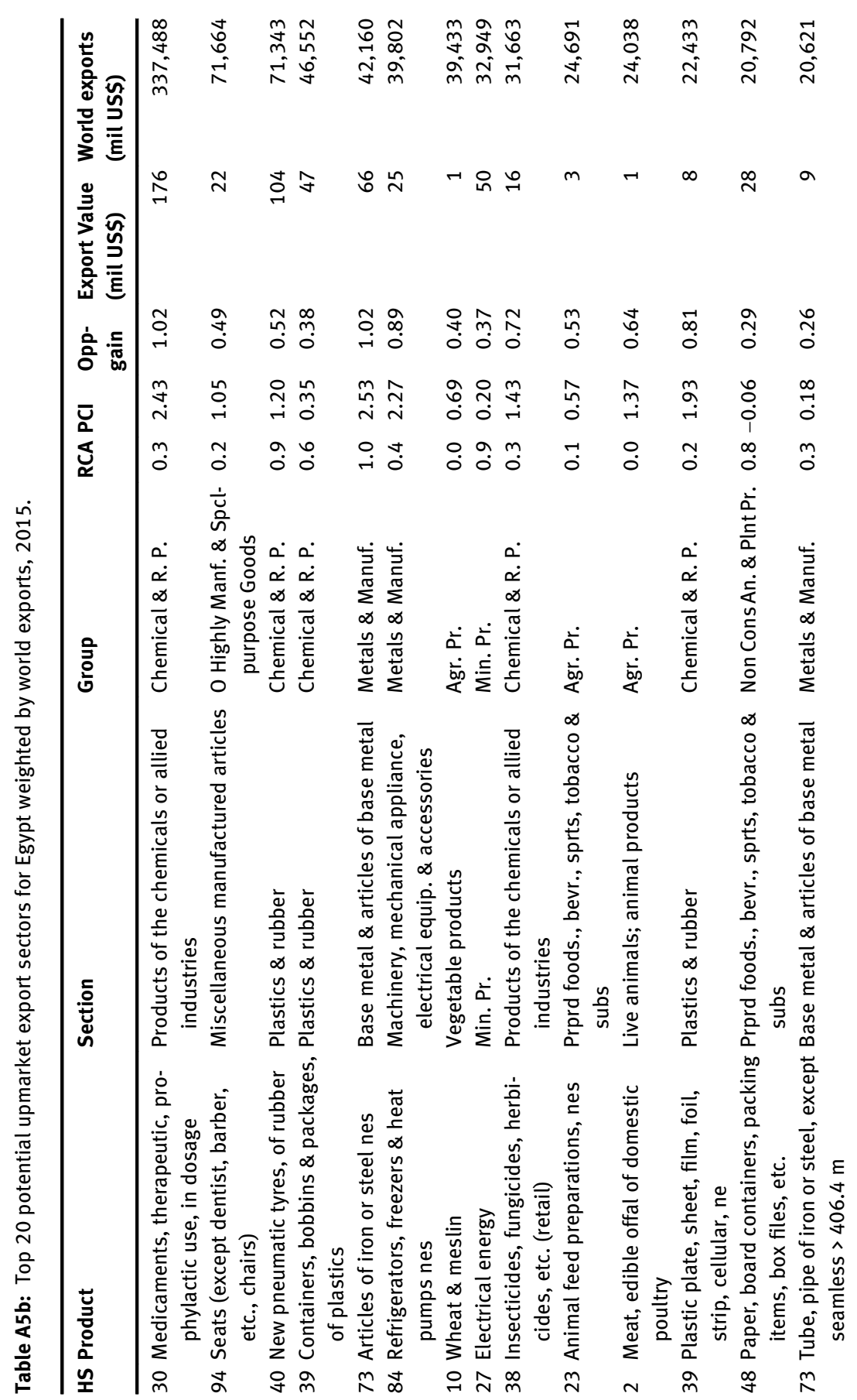




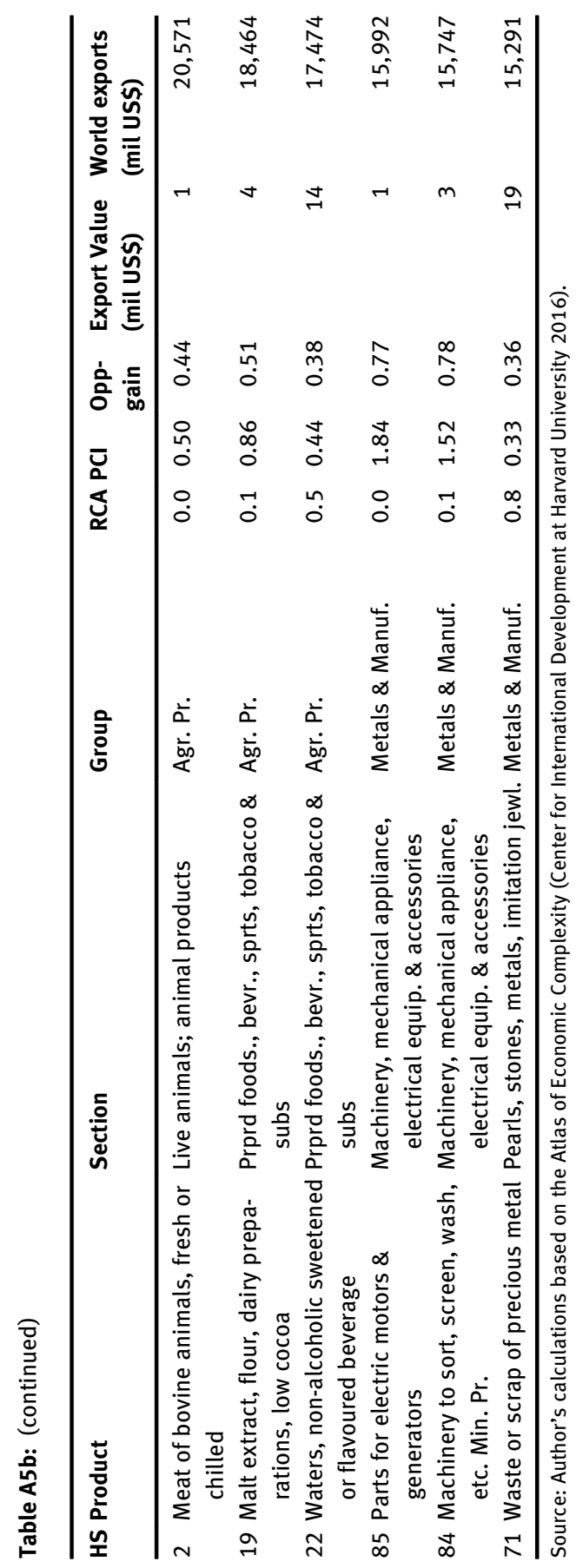




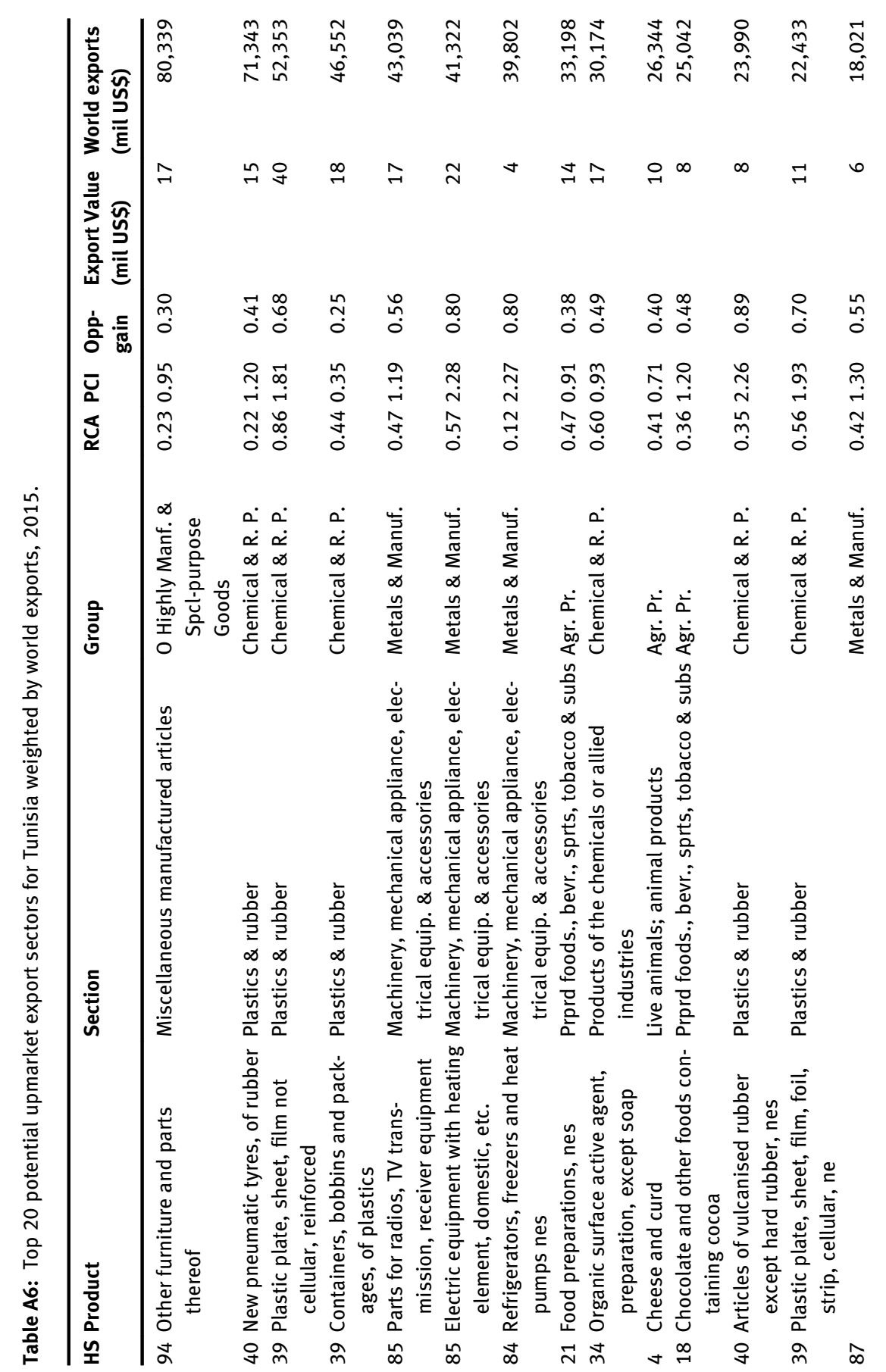




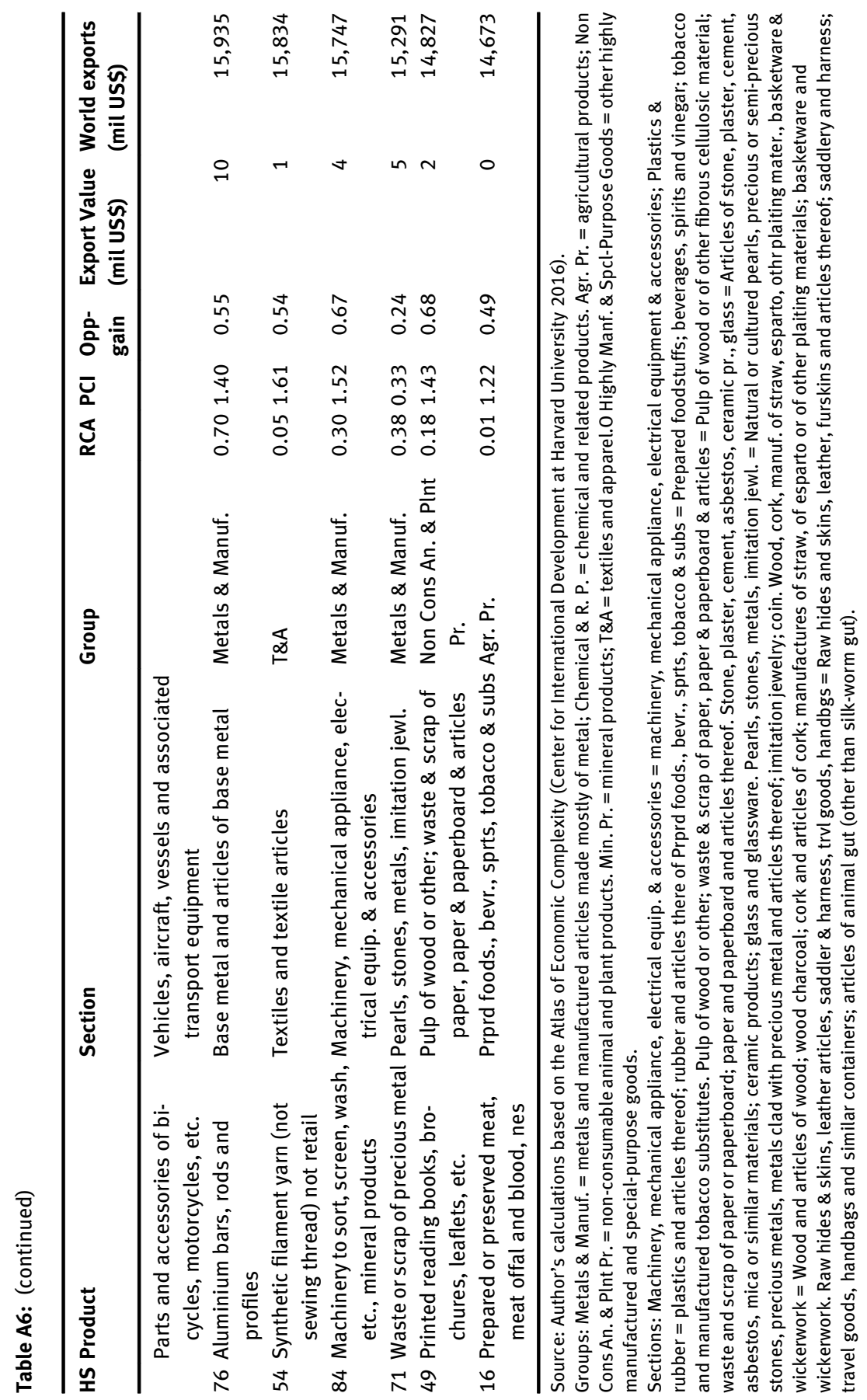




\section{Product Complexity Index (PCl)}

The PCI ranks products by the amount of capabilities or know-how necessary to manufacture them. Products such as chemicals and machinery are highly complex because they require a sophisticated level of productive knowledge and typically emerge from large organisations, where a number of highly skilled individuals interact. Whereas products such as raw materials or simple agricultural products require only a basic level of know-how and can be produced by an individual or family-run business. More specifically, the PCI ranks products by their complexity. Product complexity is determined by calculating the average diversity levels of countries that make a specific product, and the average ubiquity level of the other products that these countries make. Analogously, we define a PCI; because of the symmetry of the problem, this can be done simply by exchanging the index of countries $\mathrm{c}$ with that for products $\mathrm{p}$ in the definition in Derivation A1. Hence, PCI is defined as:

$$
\begin{aligned}
P C I & =\frac{\vec{Q}-\langle\vec{Q}>}{\operatorname{stdev}(\vec{Q})}, \vec{Q} \\
& =\text { eigenvector of } \tilde{\mathrm{M}}_{\mathrm{pp}} \text {, associated with the largest eigenvalue }
\end{aligned}
$$

(Hausmann, Hidalgo et al. 2014).

\section{References}

African Development Bank. 2000. Egypt: Economic Reform And Structural Adjustment Programme (Project Performance Evaluation Report (PPER), May 15). Available at: https://www.afdb.org/ fileadmin/uploads/afdb/Documents/Evaluation-Reports-_Shared-With-OPEV_/ 05092259-EN-EGYPT-ECONOMIC-REFORM-AND-SAP.PDF.

Al-Marhubi, F. 2000. "Export Diversification and Growth: An Empirical Investigation." Applied Economics Letters 7 (9): 559-62.

Assaad, R., and C. Krafft. 2016. Labor Market Dynamics and Youth Unemployment in The Middle East And North Africa: Evidence from Egypt, Jordan and Tunisia. (ERF Working Paper Series 993). Cairo: Economic Research Forum.

Altenburg, T. 2006. Donor Approaches to Supporting Pro-Poor Value Chains. Bonn, Germany: Report prepared for the Donor Committee for Enterprise Development.

Altenburg, T., M. Kleinz, and W. Lütkenhorst. 2016. Directing Structural Change: From Tools to Policy. (Discussion Paper 24). Bonn: German Development Institute / Deutsches Institut für Entwicklungspolitik (DIE).

Altenburg, T., and W. Lütkenhorst. 2015. Industrial Policy in Developing Countries: Failing Markets, Weak States. Cheltenham, UK: Edward Elgar. 
Antonelli, M., and M. Mariniello. 2014. Antitrust Risk in EU Manufacturing: A Sector-Level Ranking (Bruegel Working Paper 2014/07). Brussels: Bruegel.

Atallah, S., and I. Srour 2014. The Emergence of Highly Sophisticated Lebanese Exports in the Absence of an Industrial Policy (ERF Working Paper Series 876). Cairo: Economic Research Forum.

Azzam, H.T. 2013. The Emerging Arab Capital Markets: Investment Opportunities in Relatively Underplayed Markets. London and New York: Routledge.

Black. A, P. Roy, A. El-Haddad, and K.Yilmaz. 2020. The Political Economy of Automotive Industry Development Policy in Middle Income Countries: A Comparative Analysis of Egypt, India, South Africa and Turkey. Effective States and Inclusive Development Research Center (ESID) Working Paper Series, WP 143: University of Manchester. http://www.effective-states.org/ wp-content/uploads/2020/05/esid_wp_143_black_roy_haddad_yilmaz.final_.pdf.

Brenton, P., C. Saborowski, C. Staritz, and E. von Uexkull. 2009. Assessing the Adjustment Implications of Trade Policy Changes Using TRIST (tariff reform impact simulation tool) (Policy Research Working Paper Series 5045). Washington, DC: World Bank.

Bustos, S., and M. A. Yildirım. 2017. Arab Country Product Space Report: Introduction and Methodology (LCPS Policy Paper February 2017). Beirut: Lebanese Center for Policy Studies.

Cadot, O., C. Carrere, and Strauss-Kahn, V. 2008. Export Diversification: What's Behind the Hump? (CEPR discussion paper DP6590). London: Centre for Economic Policy.

Center for International Development at Harvard University. 2016. The Atlas of Economic Complexity. Retrieved from https://atlas.cid.harvard.edu/.

Cinar, S., and I. Gocer. 2014. "The Reasons and Economic and Political Consequences of Arab Spring." Journal of Humanities and Social sciences 17 (2): 39-49.

De Ferranti, D., G. E. Perry, W. Foster, D. Lederman, and A. Valdés. 2005. Beyond the City: The Rural Contribution to Development. Washington, DC: World Bank.

Diwan, I., and J. Haidar. 2016. Do Political Connections Reduce Job Creation? Evidence from Lebanon (ERF Working Paper Series 1054). Cairo: Economic Research Forum.

Djeflat, A. 2013. "The Relevance of Science and Technology for the Arab Spring and the Key Role of The Knowledge Economy." In The Real Issues of the Middle East and the Arab Spring: Addressing Research, Innovation and Entrepreneurship, edited by T. Andersson and A. Djeflat, 169-94. New York: Springer.

El-Haddad, A. 2008. "Dispute Resolution Mechanisms in the Egyptian Garment Industry." Economics Letters 99 (3): 425-30.

El-Haddad, A. 2010. "Egypt versus South Korea: Divergent Paths to Industrialization." In Role of the State in a Mixed Economy, edited by S. Abdallah, Cairo: Partners in Development (PID). https://www.pidegypt.org/publications/books/books.html https://www.pidegypt.org/ arabic/activities.htm https://www.pidegypt.org/download/mixed-economy/Dr.\%20Amira $\% 20$ El\%20Haddad.pdf.

El-Haddad, A. 2012. Effects of the Global Crisis on the Egyptian Textiles and Clothing Sector: A Blessing In Disguise? ISRN Economics 2012(941695). Retrieved from https://www.hindawi. com/isrn/economics/2012/941695/.

El-Haddad, A. 2015a. "Breaking the Shackles: The Structural Challenge of Growth and Transformation for Egypt's Industrial Sector, In Structural Transformation and Industrial Policy: A Comparative Analysis of Egypt, Morocco, Tunisia and Turkey and Case Studies." European Investment Bank 2/3: 68-107. http://www.eib.org/infocentre/publications/all/ femip-study-structural-transformation-and-industrial-policy.htm. 
El-Haddad, A. 2015b. "The Causal Chain of Market Based Reform in Egyptian Voice Telecommunication.” Journal of Development Effectiveness 7 (4): 499-512. http://www. tandfonline.com/doi/full/10.1080/19439342.2015.1105849.

El-Haddad, A. 2016. Government Intervention with No Structural Transformation: The Challenges of Egyptian Industrial Policy in Comparative Perspective (in Arabic); رؤية لاتجاهات السياسة الصناعية المصرية فى ضوء بعض الدراسات المقارنة '(ERF Working Paper Series, No. 1038). Cairo: Economic Research Forum. Retrieved from http://erf.org.eg/publications/government-interventionwith-no-structural-transformation-the-challenges-of-egyptian-industrial-policy-incomparative-perspective-in-arabic/.

El-Haddad, A. 2017. "Welfare Gains from Utility Reforms in Egyptian Telecommunication.” Utilities Policy 45: 1-26.

El-Haddad, A. 2018. Exporting for Growth: Identifying Leading Sectors for Egypt and Tunisia Using the Product Space Methodology, \#25/2018 DIE Discussion Paper. Bonn: Deutsches Institut für Entwicklungspolitik.https://www.die-gdi.de/en/discussion-paper/article/exportingfor-growth-identifying-leading-sectors-for-egypt-and-tunisia-using-the-product-spacemethodology/.

El-Haddad, A. 2020. "Redefining the Social Contract in the Wake of the Arab Spring: The Experiences of Egypt, Morocco and Tunisia." World Development 127: 104774. https://www. sciencedirect.com/science/article/pii/S0305750X19304231.

Erdle, S. 2011. Industrial Policy in Tunisia (Discussion Paper 1/2011). Bonn: German Development Institute / Deutsches Institut für Entwicklungspolitik (DIE).

Feenstra, R. C., R. E. Lipsey, H. Deng, A. C. Ma, and H. Mo. 2005. World Trade Flows: 1962-2000 (NBER Working Paper 11040). Cambridge, MA: National Bureau of Economic Research.

Fortunato, P., C. Razo, and K. Vrolijk. 2015. March). Operationalizing the Product Space: A Road Map to Export Diversification. UNCTAD/OSG/DP/2015/1. Retrieved from https://unctad.org/ en/ PublicationsLibrary/osgdp20151_en.pdf.

Gereffi, G., J. Humphrey, and T. Sturgeon. 2005. “The Governance of Global Value Chains.” Review of International Political Economy 12 (1): 78-104.

Gözgör, G., and M. Can. 2017. "Causal Linkages among the Product Diversification of Exports, Economic Globalization and Economic Growth.” Review of Development Economics 21 (3): 888-908.

Hamed, K., D. Hadi, and K. Hossein. 2014. "Export Diversification and Economic Growth in Some Selected Developing Countries." African Journal of Business Management 8 (17): 700-4.

Hausmann, R., and C. Hidalgo. 2007. The Structure of the Product Space and the Evolution of Comparative Advantage (CID Working Papers 146). Cambridge, MA: Center for International Development at Harvard University.

Hausmann, R., C. Hidalgo, S. Bustos, M. Coscia, S. Chung, J. Jimenez, A. Simoes, and M. Yildirim. 2011. The Atlas of Economic Complexity: Mapping Paths to Prosperity. Cambridge, MA: Center for International Development at Harvard University, and MIT Press.

Hausmann, R., C. A. Hidalgo, S. Bustos, M. Coscia, A. Simoes, and M. A. Yildirim. 2014. The Atlas of Economic Complexity: Mapping Paths to Prosperity. Cambridge, MA: The MIT Press.

Hausmann, R., J. Hwang, and D. Rodrik. 2005. What You Export Matters (NBER Working Paper 11905). Cambridge, MA: National Bureau of Economic Research.

Hausmann, R., and B. Klinger. 2006. Structural Transformation and Patterns of Comparative Advantage in the Product Space (CID Working Paper No. 128). Cambridge, MA: Center for International Development at Harvard University. 
Hausmann, R., and B. Klinger. 2007. The Structure of the Product Space and the Evolution of Comparative Advantage (CID Working Paper 146). Cambridge, MA: Center for International Development at Harvard University.

Hausmann, R., B. Klinger, and J. Lopez-Calix. 2010. “Export Diversification in Algeria.” In Trade Competitiveness of the Middle East and North Africa, edited by J. R. López-Cálix, P. Walkenhorst, and N. Diop, 63-102. Washington, DC: World Bank.

Hausmann, R., J. Matovu, R. Osire, and K. Wyett. 2014. How Should Uganda Grow? (ESID Working Paper 30). Manchester, UK: Effective States and Inclusive Development Research Centre.

Hausmann, R., L. Tyson, and S. Zahidi. 2009. The Global Gender Gap Report 2009. Geneva: World Economic Forum.

Hertog, S. 2017. "The Political Economy of Distribution in the Middle East: Is There Scope For A New Social Contract?." International Development Policy 7. Retrieved from https://journals. openedition.org/poldev/2270.

Herzer, D., and D. F. Nowak-Lehnmann. 2006. "What Does Export Diversification Do For Growth? An Econometric Analysis.” Applied Economics 38 (15): 1825-38.

Hidalgo, C., and R. Hausmann. 2009. "The Building Blocks of Economic Complexity.” Proceedings of the National Academy of Sciences 106 (26): 10570-5. https://www.jstor.org/stable/ 40483593.

Hidalgo, C., B. Klinger, A. Barabási , and R. Hausmann. 2007. "The Product Space Conditions the Development of Nations." Science 317 (5837): 482-7.

Hirschman, A. 0. 1969. "The Strategy of Economic Development." In Accelerating Investment in Developing Economies, edited by A. N. Agarwala and S. P. Singh, 3-11. London: Oxford Press.

Hosseini, S., and C. Tang. 2014. "The Effects of Oil And Non-Oil Exports on Economic Growth: A Case Study of The Iranian Economy.” Economic Research-Ekonomska Istraživanja 27 (1): 427-41.

ILO (International Labour Organization). 2020. ILOSTAT Database [database]. Retrieved from https://ilostat.ilo.org/data/.

International Monetary Fund. 2009. Regional Economic Outlook: Middle East and Central Asia. World Economic and Financial Surveys. Retrieved from https://www.imf.org/external/pubs/ $\mathrm{ft} / \mathrm{reo} / 2009 / \mathrm{mcd} / \mathrm{eng} / \mathrm{mreo0509}$.pdf.

Klinger, B., and D. Lederman. 2004. Discovery and Development: An Empirical Exploration of "new" Products (Policy Research Working Paper 3450). Washington, DC: World Bank.

Kalaitzi, S., and T. W. Chamberlain. (Forthcoming). Further Evidence on Export-led growth in the United Arab Emirates: Are Non-Oil Exports or Re-Exports the Key to Economic Growth? Review of Middle East Economics and Finance.

Kalaitzi, S., and E. Cleeve. 2017. "Export-led Growth in The Uae: Multivariate Causality Between Primary Exports, Manufactured Exports And Economic Growth." Eurasian Business Review 8 (3): 341-65.

Kuznets, S. 1971. Economic Growth of Nations: Total Output and Production Structure. Cambridge, MA: The Belknap Press of Harvard University Press.

Loewe, M. 2013. Industrial Policy in Egypt 2004-2011 (Discussion Paper 13/2013). Bonn: German Development Institute / Deutsches Institut für Entwicklungspolitik (DIE).

McCormick, D., and H. Schmitz. 2001. Manual for Value Chain Research on Homeworkers in the Garment Industry. Retrieved from https://www.ids.ac.uk/ids/global/wiego.html.

Nabli, M. K. 2007. "Alternative Trade Policies and Employment in Tunisia." In Trade and Employment in Developing Countries, Volume 1: Individual Studies, Edited by A. O. Krueger, H. B. Lary, Terry Monson, and N. Akrasanee. Chicago: University of Chicago Press. 
Pasinetti, L. L. 1981. Structural Change and Economic Growth. Cambridge: Cambridge University Press.

Radosevic, S. 2017. “Assessing EU Smart Specialization Policy in a Comparative Perspective: The Emerging Issues." In Advances in theory and practice of smart specialization, edited by S. Radosevic, A. Curaj, R. Gheorghiu, L. Andreescu, and I. Wade, 1-36. Amsterdam: Elsevier Science Publishers.

Ricardo, D. 1817. On the Principles of Political Economy and Taxation. London: John Murray. Rivlin P. 2009. Arab Economies in the Twenty-First Century. New York: Cambridge University Press. Rodrik, D. 2007. Normalizing Industrial Policy. Cambridge, MA: John F. Kennedy School of Government, Harvard University.

Sannassee, R. V., B. Seetanah, and M. J. Lamport. 2014. "Export Diversification and Economic Growth: The Case of Mauritius." In Connecting to Global Markets: Challenges and Opportunities, edited by M. Jansen, M. S. Jallab, and M. Smeets, 11-23. Geneva: World Trade Organization.

Schmitz, H., and P. Knorringa. 1999. Learning from Global Buyers (IDS Working Paper 100). Brighton: Institute of Development Studies.

Singer, H. 1958, April. The Concept of Balanced Growth and Economic Development; Theory and Facts. University of Texas Conference on Economic Development.

Streeten, P. 1969. "Unbalanced Growth. Economic Integration, Sythoff, Leiden (Netherlands), 1961." Reprinted in Accelerating Investment in Developing Economies, edited by A. N. Agarwala and S. P. Singh. London: Oxford Press.

United Nations Industrial Development Organization. 2005. UNIDO Technology Foresight Manual: Organization and Methods. Vienna: Author.

van Eekelen, W., L. de Luca, and N. Ismail. 2001. Youth Employment in Egypt (ILO Skills Working Paper No. 2). Geneva: ILO.

Vidican, G., M. Böhning, G. Burger, E. de Siqueira Regueira, S. Müller, and S. Wendt. 2013. Achieving Inclusive Competitiveness in the Emerging Solar Energy Sector in Morocco (Study 79). Bonn: German Development Institute / Deutsches Institut für Entwicklungspolitik (DIE).

Weipert-Fenner, I. and J. Wolff. 2020. "From North Africa to Latin America and back: Comparative findings and Theoretical Reflections." In Socioeconomic protests in MENA and Latin America. Egypt and Tunisia in Interregional Comparison, edited by I. Weipert-Fenner and J. Wolff, 251-74. Cham: Palgrave Macmillan.

WITS (World Integrated Trade Solution). 2016. UNCTAD Trade Information and Analysis System (TRAINS) database through the World Integrated Trade Solution. Retrieved from https://wits. worldbank.org.

World Bank. 2016. World Development Indicators Database. Retrieved from https://data. worldbank.org/data-catalog/world-development-indicators. 